\title{
Removal of heavy metals by homolytically functionalized poly(acrylic acid) with hydroquinone
}

\author{
Saâd Moulay ${ }^{1} \cdot$ Nabila Bensacia $^{1}$
}

Received: 25 June 2015/Accepted: 28 August 2016/Published online: 12 September 2016

(C) The Author(s) 2016. This article is published with open access at Springerlink.com

\begin{abstract}
Poly(acrylic acid) (PAA) was synthesized and chemically modified with hydroquinone (HQ) applying the reaction conditions of Minisci. A degree of modification of as high as $32 \%$ was obtained under optimal conditions: temperature of $70-80{ }^{\circ} \mathrm{C}$, time of $5 \mathrm{~h}$, and [p-benzoquinone]/[acrylic acid)] ratio of 1.25 . The synthesized PAA and its modified form HQ-PAA were characterized by UV-visible, FT-IR, XRD, SEM, ${ }^{13} \mathrm{C}$ NMR spectroscopy, TGA, DSC, and size exclusion chromatography. The study of copper (II) adsorption by the cross-linked PAA and HQPAA resins was undertaken, varying the following parameters: $\mathrm{pH}$, time, temperature, ionic strength, sorbent mass, and initial copper (II) concentration. Optimal copper sorption extents of 5.5 and $20 \mathrm{mg} \mathrm{g}^{-1}$ for PAA and HQPAA resins, respectively, were found under the following conditions: a $\mathrm{pH}$ of 5.4, a time of $3 \mathrm{~h}$, a temperature of $45^{\circ} \mathrm{C}$, and an ionic strength of 0 . Sorbent resins were achieved by cross-linking poly(acrylic acid) and its modified one through an oxidative decarboxylation process.
\end{abstract}

Keywords Copper - Hydroquinone - Metallic adsorption · Poly(acrylic acid)

Saâd Moulay

polymchemlab@hotmail.com; saadmoulay@univ-blida.dz

1 Laboratoire de Chimie-Physique Moléculaire et Macromoléculaire, Département de Chimie Industrielle, Faculté de Technologie, Université Saâd Dahlab de Blida, B. P. 270, Route de Soumâa, 09000 Blida, Algeria

\section{Introduction}

Polyacrylics are a special class of polymers as far as their uses, and applications are of interest. Their nowadays ubiquity stems from the large spectrum of their properties which are on a par with the chemical reactivity of their functional groups, i.e., carboxylic, ester, amide, and nitrile. A wide range of their chemical modifications are, but the result of the proneness of these groups to chemical reactions, affording valuable materials with targeted properties. Poly(acrylic acid) (PAA), coined the name "carbopol" in pharmaceuticals, is known to be a super absorbent polymer that can absorb and retains a great extent of water, a property that is exploited in hydrogels making for various controlled drug delivery systems $[1,2]$; a related fact is that the swelling behavior of PAA hydrogels was found to be highly medium $\mathrm{pH}$ dependent due to the presence of carboxylic groups [3]. Low molecular weight PAA has been valorized as an efficient salt-scaling inhibitor, chiefly in oilfield operations, via the ability of the carboxylic groups in sequestering metal ions [4]. A five-fold enhancement in the removal heavy metals was observed with PAA-bound tetrahydroxybenzene (THB-PAA) with respect to the virgin PAA [5]. Pyridylazo-2-naphthol-functionalized PAA was employed as a fluorescent nanofiber probe for the determination of $\mathrm{Ni}^{2+}$ [6]. Besides of being water soluble, PAA has a capacity to form polyelectrolyte complex nanoparticles with other polymers, such as poly(ethyleneimine) [7]. Ultrathin films for electrochromic devices were made via a layer-by-layer (LBL) strategy by reacting PAA with polyaniline in acid-base $\left(\mathrm{COOH} / \mathrm{NH}_{2}\right)$ mechanism [8]. By the virtue of its carboxylic groups, PAA served as template for making helical polyaniline-PAA microwires or rods [9]. The plausible decarboxylation of PAA via a homolytic pathway promoted its use as a redox 
unit carrier [10]. Apart from its hydrophilic character, PAA via its carboxylic groups was of a critical value in coating bleomycin-loaded magnetite nanoparticles $\left(\mathrm{Fe}_{3} \mathrm{O}_{4}\right)$ to generate an antitumoral drug delivery system [11]. As for polycarboxylic acids [12], the other facet of PAA is its propensity towards potentiometric titration. The latter property is of a great merit, because the $\mathrm{pH}$ plays a pivotal role in several investigations, indicating the actual form of the involved molecule (ionized and neutral species). Moreover, the polymer effect emerges in various chemical studies as the results using polymers may be different from those using their molecular counterparts; for example, the potentiometric titration of PAA exhibits a profile different from those of acrylic acid and acetic acid.

In a continuation of a previous work [5, 13, 14], it is herein intended in the present paper to apply the chemistry of Minisci [15] at the macromolecular level, and henceforth to the chemical modification of poly(acrylic acid) (PAA) with hydroquinone (HQ); the latter one, being a polyhydroxylated benzene, is conceived as ligating species in the removal of heavy metallic ions via adsorption process. A synergism of $\mathrm{COOH}$ and $\mathbf{H Q}$ functionalities within the polymeric material in the removal of heavy metals is herein demonstrated; introducing HQ moieties onto PAA matrix would enhance the metal adsorption capacity of this polymer. Recently, we reported the results of adsorption of cadmium and led by $\mathrm{COOH}$-functionalized mesoporous silica [16, 17]. Resins containing catechol and resorcinol were evaluated as sorbents for heavy metal ions [18, 19]. The present study includes the preparation of the HQ-PAA resin and an observation of the effects of reaction time and benzoquinone/monomer unit molar ratio on the degree of substitution, and of the effects of several experimental parameters, such as contact time, initial $\mathrm{pH}$, electrolyte concentration, temperature, and initial resin mass, and copper concentration on the capacity exchange in the metal adsorption. The adsorption kinetics and isotherm models were used to describe the copper adsorption data. The thermodynamic factors of adsorption were determined.

\section{Experiment}

\section{Materials and measurements}

The chemicals were purchased from one of the following chemical companies: Aldrich (France), Fluka AG, Prolabo, and Merck. Acrylic acid was purified by vacuum distillation. Azobisisobutyronitrile (AIBN) was recrystallized from methanol. 1,4-Benzoquinone (BQ) was used as purchased. UV-vis spectra were recorded using a JASCO UV-
Vis spectrophotometer using bidistilled water as a solvent. Infrared spectra were taken with a JASCO 4200 FT-IR. The polymer samples for the infrared analysis were in the form of cast films. The diagrams of X-ray diffraction (XRD) were recorded on a Bruker D8 diffractometer (K radiation, $\lambda=0.154 \mathrm{~nm}, 40 \mathrm{kV}, 100 \mathrm{~mA}$ ). The experiments were performed directly on the polymer samples which were finely cut in the range of $2 \theta$ equal to $5^{\circ}-90^{\circ}$ at the scanning speed of $0.02 \%$. The morphology of polymeric samples was observed using a scanning electron microscope (SEM) JEOL 6700 operating at an acceleration voltage of $200 \mathrm{kV} .{ }^{13} \mathrm{C} \mathrm{NMR}$ spectra were recorded using a spectrometer Bruker $400 \mathrm{MHz}$ using $\mathrm{CD}_{3} \mathrm{OD}$ as the solvent. Molecular weights were measured by size exclusion chromatography (SEC) [gel permeation chromatography (GPC)] on a set DIONEX, series Ultimate 3000 (degasser, pump, autosampler), 4 Shodex $\mathrm{OH}$-pack $30 \mathrm{~cm}$ in series (803HQ, 804HQ, 806HQ, and 807HQ), a differential refractometer OPTILABrEX (Wyatt Tech), and a lightscattering detector DAWN multiangle HELEOSII (Wyatt Tech). The eluent was an aqueous solution consisting of water and $0.1 \mathrm{M} \mathrm{NaNO}_{3}$ at a rate of $0.5 \mathrm{~mL} \mathrm{~min}^{-1}$. The injected volume was $0.1 \mathrm{~mL}$ from a concentration of 2-3 $\mathrm{g} \mathrm{mL}^{-1}$ of each polymer solution. Differential scanning calorimetry (DSC) thermograms were recorded on Netzsch DSC $204 \mathrm{~F} 1$ at a heating rate of $5{ }^{\circ} \mathrm{C} \mathrm{min}{ }^{-1}$ under nitrogen atmosphere. Thermogravimetric analysis (TGA) was conducted on NETZSCH TG 209 F3 apparatus in the temperature interval of $20-600{ }^{\circ} \mathrm{C}$, at a heating rate of $10{ }^{\circ} \mathrm{C} \mathrm{min}{ }^{-1}$ under nitrogen atmosphere $\left(2 \mathrm{~mL} \mathrm{~min}^{-1}\right)$. The used weights of polymer samples for the measurement were in the range of 5.5-5.7 $\mathrm{mg}$. Metallic adsorption by resins was estimated by flame atomic absorption spectrometer (FAAS) of type Buck Scientifics 210VGP fitted with a deuterium lamp, a corresponding hollow cathode lamp, and a 10-cm long burner; the flame was provided by air-acetylene gas.

\section{Modification reactions of poly(acrylic acid) PAA (Eq. 1)}

In a $500 \mathrm{~mL}$, one-neck round bottom flask equipped with a condenser $0.5 \mathrm{~g}\left(6.94 \times 10^{-3} \mathrm{~mol}\right)$ of PAA was dissolved in $50 \mathrm{~mL}$ of distilled water, followed by the addition of $50 \mathrm{~mL}$ of an ethanolic solution containing $0.93 \mathrm{~g}$ $\left(8.6 \times 10^{-3} \mathrm{~mol}\right)$ of BQ. To this homogeneous mixture, $0.039 \mathrm{~g}\left(2.3 \times 10^{-4} \mathrm{~mol}\right)$ of silver nitrate was added, followed by the addition of $150 \mathrm{~mL}$ of distilled water. The system was heated to reach $75-80{ }^{\circ} \mathrm{C}$ under magnetic stirring. Once this temperature was reached, a saturated solution of potassium persulfate $\left(1.88 \mathrm{~g}, 6.95 \times 10^{-3} \mathrm{~mol}\right)$ 
was added dropwise. The reaction was stopped, and the content was cooled to room temperature. The modified PAA was isolated by the following sequential steps: (1) the evaporation of ethanol followed by the addition of $50 \mathrm{~mL}$ of distilled water; (2) the mixture was allowed to stand for 1 day to assure the precipitation of the unreacted BQ (the precipitate was eliminated by filtration); and (3) the modified PAA was obtained by casting from the solution within 4 days. The cast film was then dried to constant weight in vacuo at $45{ }^{\circ} \mathrm{C}$ for 4 days.

The modified PAA is herein abbreviated as HQ-PAA. provided by Eq. (3); $m$ is the sample weight of the HQPAA used in the UV measurements; $M_{1}$ and $M_{2}$ are the molecular weights of acrylic acid and vinyl hydroquinone, respectively.

\section{Metallic ion adsorption}

Preparation of the resins (Eqs. 4 and 5)

Into a $100 \mathrm{~mL}$ round-bottomed flask fitted with a reflux condenser, $5 \mathrm{~g}$ of polymer were charged and dissolved in

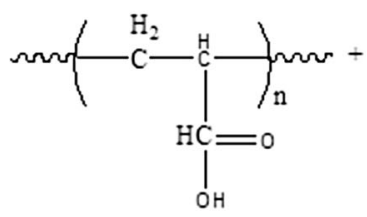

PAA<smiles>[Y6][C@H](C)[N+](=O)[O-]</smiles>

BQ

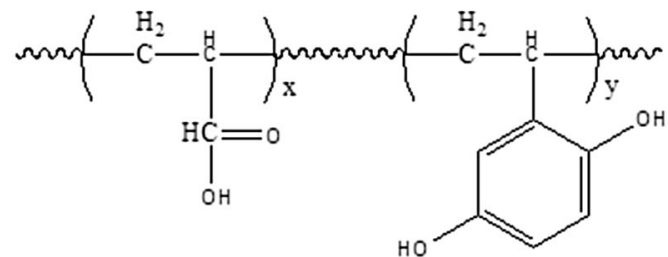

HQ-PAA
The degree of substitution $S(\%)$ was provided by the following equations (Eqs. 2, 3) [10, 20]:

$$
\begin{aligned}
& S \%=\frac{n_{2}}{n_{1}+n_{2}} \\
& n_{1}=\frac{m-n_{2} M_{2}}{M_{1}}
\end{aligned}
$$

where $n_{2}$ is the number of moles of $\mathbf{H Q}$ (in the form of vinyl hydroquinone) present in the modified PAA, estimated from the UV calibration curve of $\mathbf{H Q} ; n_{l}$ is the number of moles of acrylic acid present in the HQ-PAA,
$100 \mathrm{~mL}$ of distilled water. An amount of $0.39 \mathrm{~g}$ $\left(2.3 \times 10^{-3} \mathrm{~mol}\right)$ of $\mathrm{AgNO}_{3}$ was added, and the mixture was heated while stirring at a temperature of $70-75{ }^{\circ} \mathrm{C}$, then a $100 \mathrm{~mL}$ aqueous solution of $1.88 \mathrm{~g}$ $\left(6.96 \times 10^{-3} \mathrm{~mol}\right)$ of $\mathrm{K}_{2} \mathrm{~S}_{2} \mathrm{O}_{8}$ was added dropwise to the mixture. The latter was allowed to stir at this temperature domain for almost $1 \mathrm{~h}$, the time after which a precipitate was observed. The precipitate was isolated and washed with a plenty of water and dried to a constant weight in vacuo for 4 days at a temperature of $45{ }^{\circ} \mathrm{C}$. 


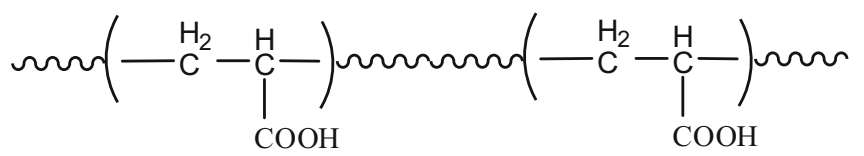

$$
\begin{aligned}
& \mathrm{K}_{2} \mathrm{~S}_{2} \mathrm{O}_{8} / \mathrm{AgNO}_{3}
\end{aligned}
$$

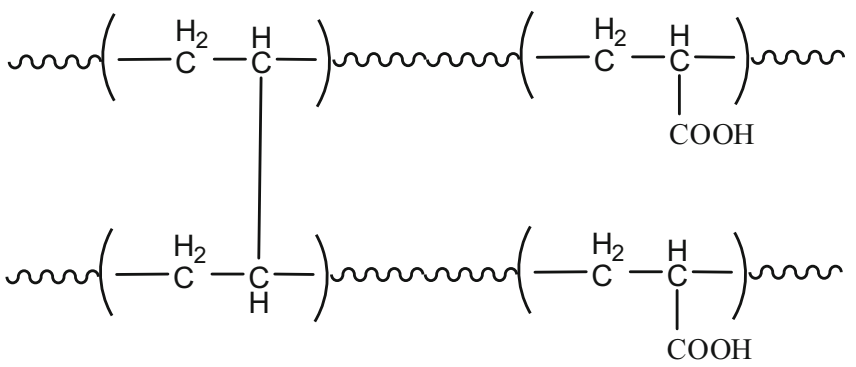

PAA resin

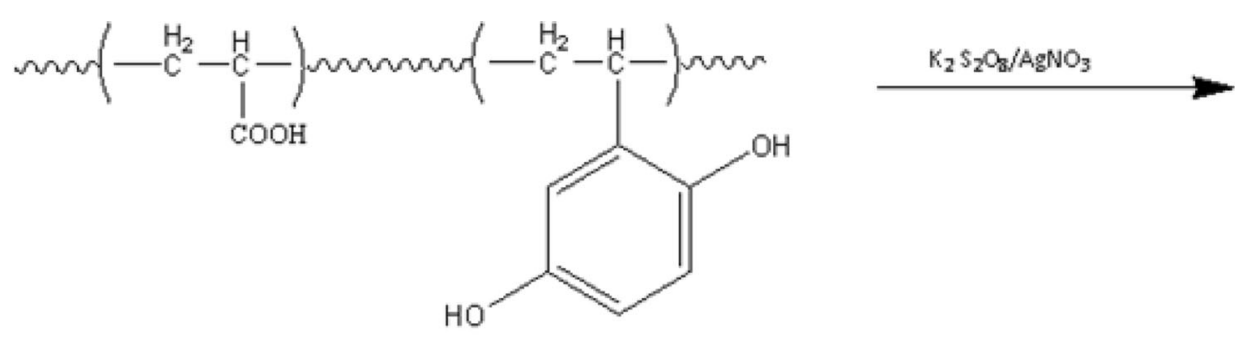

HQ-PAA

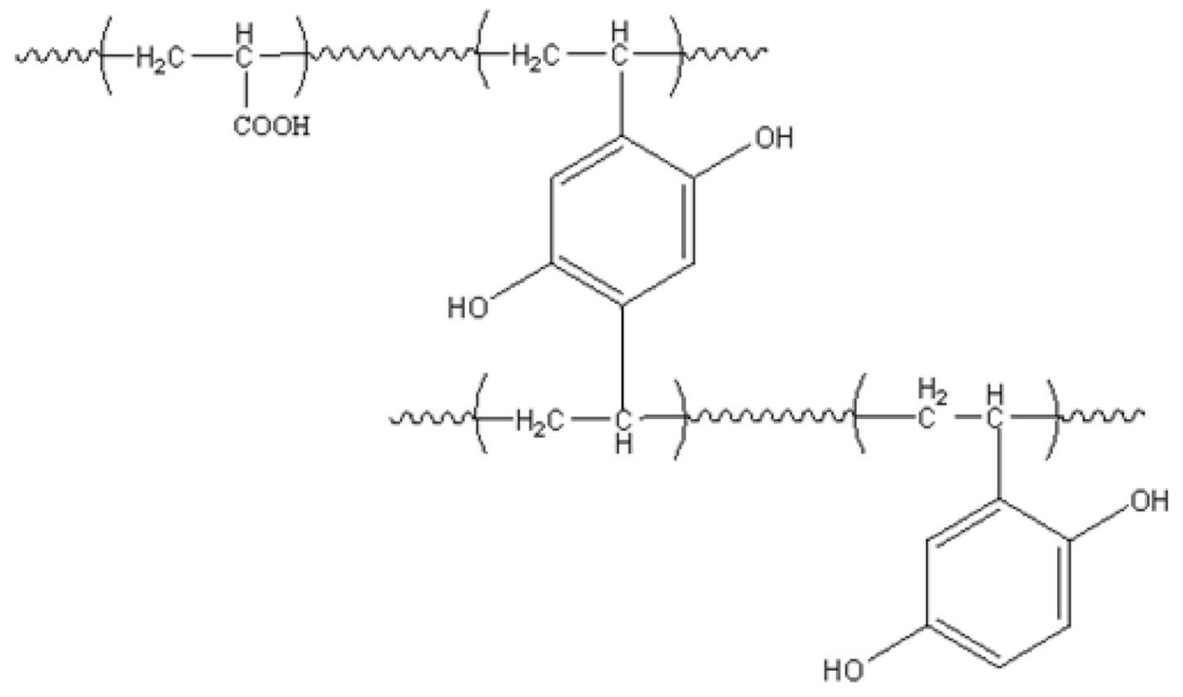




\section{Metal ion adsorption/desorption}

In a thermostated cell, $0.1 \mathrm{~g}$ of cross-linked resin was added to $50 \mathrm{~mL}$ of $50 \mathrm{mg} \mathrm{L}{ }^{-1} \mathrm{Cu}\left(\mathrm{NO}_{3}\right)_{2}$ aqueous solution, which was previously adjusted to a desired $\mathrm{pH}$ (with $0.1 \mathrm{~N}$ $\mathrm{HCl}$ and $0.1 \mathrm{~N} \mathrm{NaOH}$ ). The system was stirred with a magnetic bar at a temperature of $30{ }^{\circ} \mathrm{C}$. Sampling of the supernatant liquid was realized at specified time intervals. The adsorption capacity $Q_{t}$ (in $\mathrm{mg}$ of copper per gram of resin) [21] was computed from Eq. 6:

$Q_{t}=\frac{\left(C_{0}-C_{\mathrm{e}}\right) \cdot V}{W}$

where $C_{0}, C_{\mathrm{e}}, V$, and $W$ are the initial copper concentration in the aqueous solution ( $\left.\mathrm{mg} \mathrm{L}^{-1}\right)$, the copper concentration at equilibrium $\left(\mathrm{mg} \mathrm{L}^{-1}\right)$, the volume of aqueous solution (L), and the weight of the resin ( $\mathrm{g}$ ), respectively. A triplicate adsorption analysis was undertaken, and the mean values were considered.

The desorption of metal ion from the dried loaded resin $(0.2 \mathrm{~g})$ was conducted using $0.1 \mathrm{~N} \mathrm{HNO}_{3}(50 \mathrm{~mL})$ at $30{ }^{\circ} \mathrm{C}$ for $3 \mathrm{~h}$. The regenerated resin was subjected to two other adsorption-desorption cycles. The desorption percentage $\boldsymbol{D P}$ [22] was calculated according to Eq. 7: $\begin{aligned} \boldsymbol{D P}= & \frac{\text { Amount of metallic ion desorbed in the medium }}{\text { Amount of metallic ion present in the resin }} \\ & \times 100 .\end{aligned}$

\section{Results and discussion}

\section{Chemical modification of PAA}

Poly(acrylic acid) was synthesized as previously reported [5] and subjected to chemical reaction with $p$-benzoquinone by the virtue of the oxidative decarboxylation conditions of Minisci [13], as traced in Eq. 1. The mechanism proposed for such a chemical modification is depicted in Scheme 1 [23]. The system $\mathrm{K}_{2} \mathrm{~S}_{2} \mathrm{O}_{8} / \mathrm{AgNO}_{3}$ induced the formation of a polymeric radical PAA: Being an electron-rich site and behaving as a nucleophilic alkyl, the latter radical readily reacted with a benzoquinone compound, acting as an electron-deficient species. Minisci advanced such a mechanistic explanation for the homolytic alkylation of pyridine and its derivatives [24, 25]. Nucleophilic alkyl radicals were reported to attack preferentially the carbon atom of the benzoquinone compound [24].
Scheme 1 Mechanism of the grafting of hydroquinone (HQ) on poly(acrylic acid)
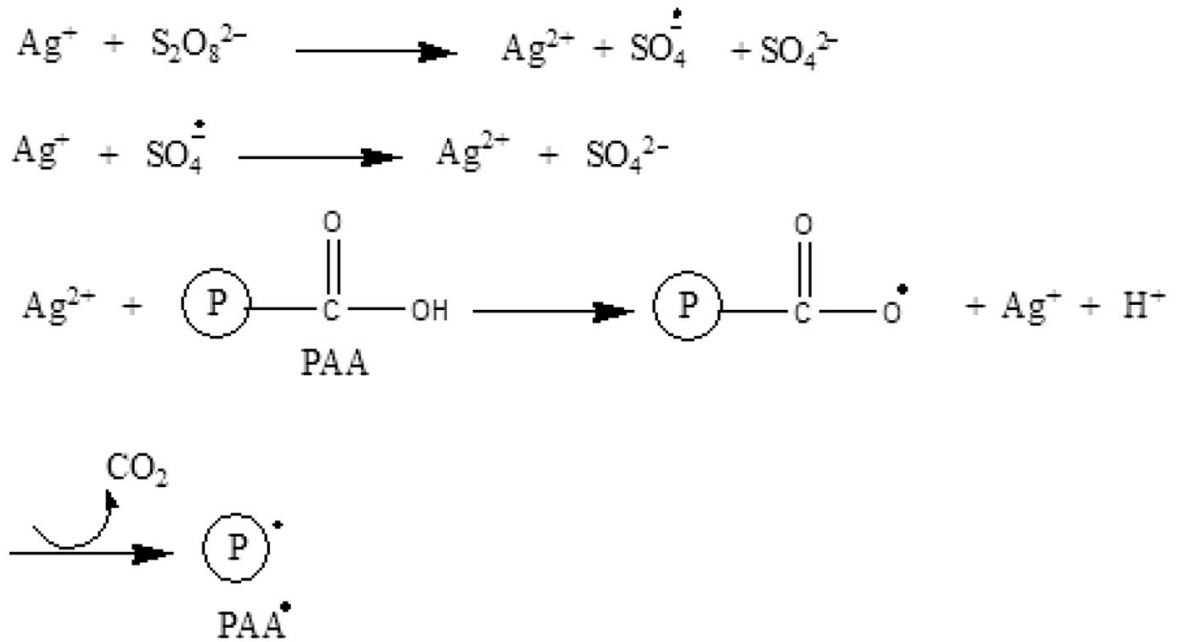

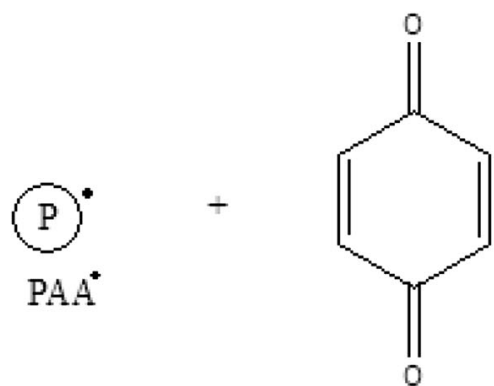

BQ

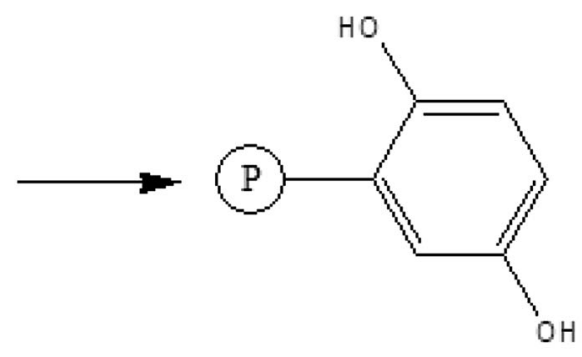

HQ-PAA 


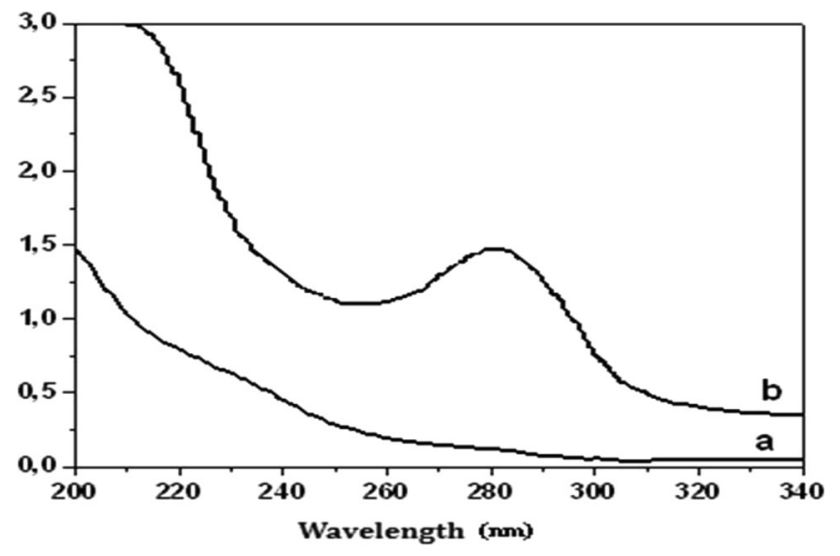

Fig. 1 UV-visible spectra: a PAA; b HQ-PAA ([BQ]/[AA] = 1.25). Solvent: bidistilled water

Modified PAA displayed similar traits to the pristine polymer in terms of solubility, that is, HQ-PAA was soluble in polar solvents, such as water, methanol, dioxane, THF, and DMF and defied solubility in non-polar organic solvents.

Analyses by UV-visible, FT-IR, XRD, SEM, and ${ }^{13} \mathrm{C}$ NMR (Figs. 1, 2, 3, 4, 5) certified the success of chemical modifications of PAA with HQ. UV-visible spectrum of HQ-PAA (Fig. 1) reveals a new absorption band at $\lambda_{\text {max }}=288 \mathrm{~nm}$, a featuring band of a hydroquinone unit. In addition, the infrared analysis (Fig. 2) came up with new absorption bands for HQ-PAA compared with those of virgin PAA. As can be clearly seen, it seems that the incorporation of HQ units onto PAA matrix has helped resolving its FT-IR spectrum, hinting at a high and regular substitution. The characteristic bands of the HQ entity appeared clearly as: (1) bands at around 1500-1550 $\mathrm{cm}^{-1}$, assigned to the aromatic $\mathrm{C}=\mathrm{C}$ stretching; (2) two sharper bands at $860-870$ and $1200-1250 \mathrm{~cm}^{-1}$, attributable to the angular deformation of $\mathrm{C}=\mathrm{C}$ and the stretching of $\mathrm{C}-\mathrm{O}$, respectively; (3) a band at $1400-1425 \mathrm{~cm}^{-1}$, assigned to planar $\mathrm{C}-\mathrm{H}$ band of the benzene ring; and (4) a wide band at around $3400 \mathrm{~cm}^{-1}$, ascribed to $\mathrm{O}-\mathrm{H}$ band.

The analysis by ${ }^{13} \mathrm{C}$ NMR spectroscopy further supported the success of the chemical modification of poly(acrylic acid) (Fig. 3). Indeed, besides the chemical shifts of different carbons of PAA appearing at around of 36-42, 44-54, and 178-180 ppm, those of the HQ units are 112-116, 130, and $150 \mathrm{ppm}$.

Figure 4 illustrates the XRD patterns of PAA and HQPAA, indicating amorphous structures for both polymers as reported by other workers [26]. In the diffractogram of HQPAA, new peaks at $2 \theta$ equal to 27,32 , and $45^{\circ}$ appeared, suggesting that a degree of crystallinity was ensued. Our results are consistent with the reported ones [27], confirming the grafting of $\mathbf{H Q}$ in the structure of the modified PAA.

SEM images of PAA and HQ-PAA are depicted in Fig. 5. The texture of PAA (Fig. 5a) is relatively flat and smooth, compared to that of HQ-PAA (Fig. 5b, c) which shows roughened surfaces filled with needles. This change proved the grafting of HQ within the PAA chains.

Surprisingly, the average molecular weight (Fig. 6; Table 1) of HQ-PAA was nearly unchanged or slightly lower than that of the starting PAA. Indeed, $M_{\mathrm{w}}$ of the modified $\mathbf{H Q}_{\mathbf{x}}$-PAA ( $\mathbf{x}$, a degree of substitution equal to $32 \%$ ) was estimated as $2.38 \times 10^{6} \mathrm{~g} \mathrm{~mole}^{-1}$ against $2.54 \times 10^{6} \mathrm{~g} \mathrm{~mole}^{-1}$ for PAA; that is, the mass of the modified polymer was about 1.06 times lower than the initial molecular weight of PAA, suggesting a degradation

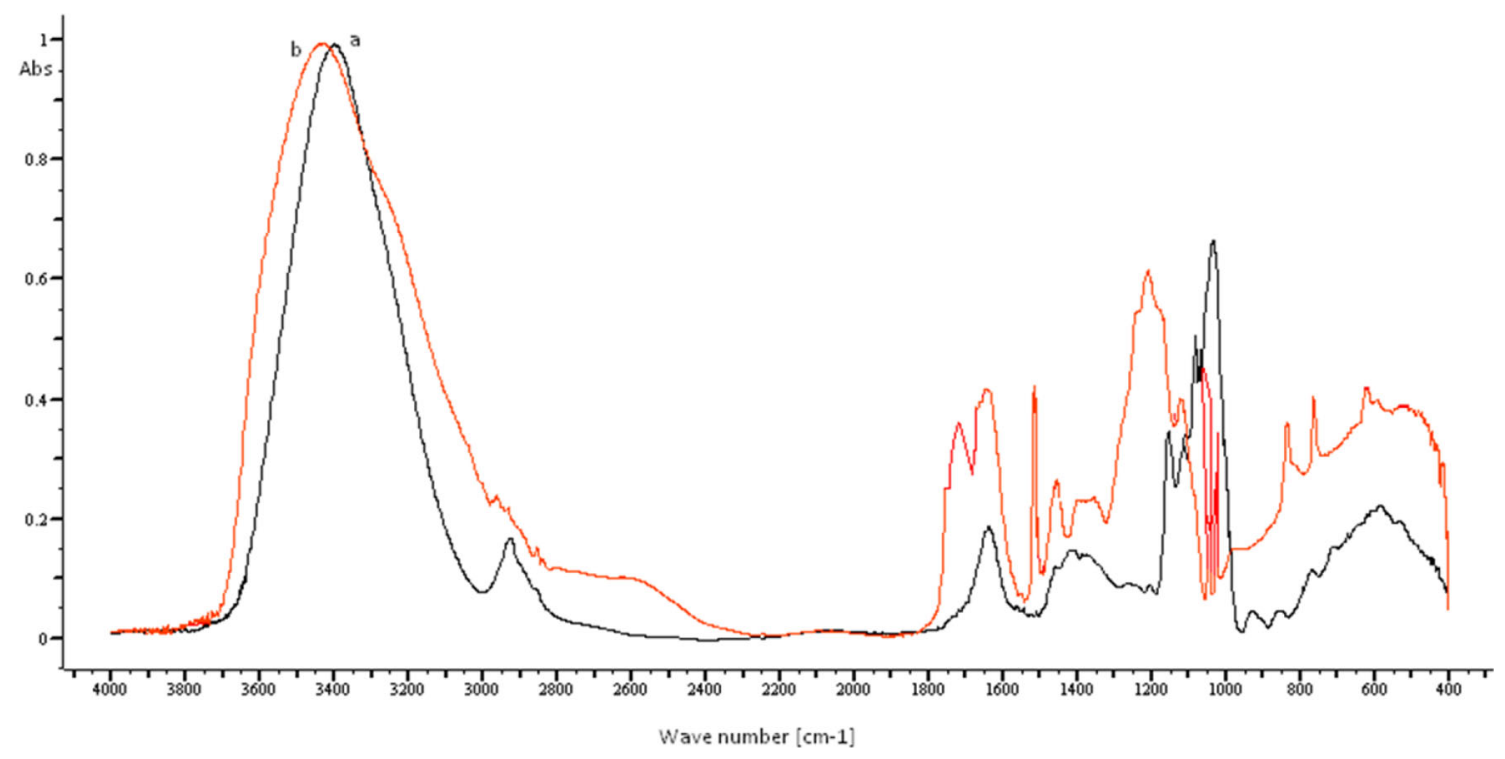

Fig. 2 FT-IR spectra: a PAA; b HQ-PAA ([BQ]/[AA] = 1.25) 

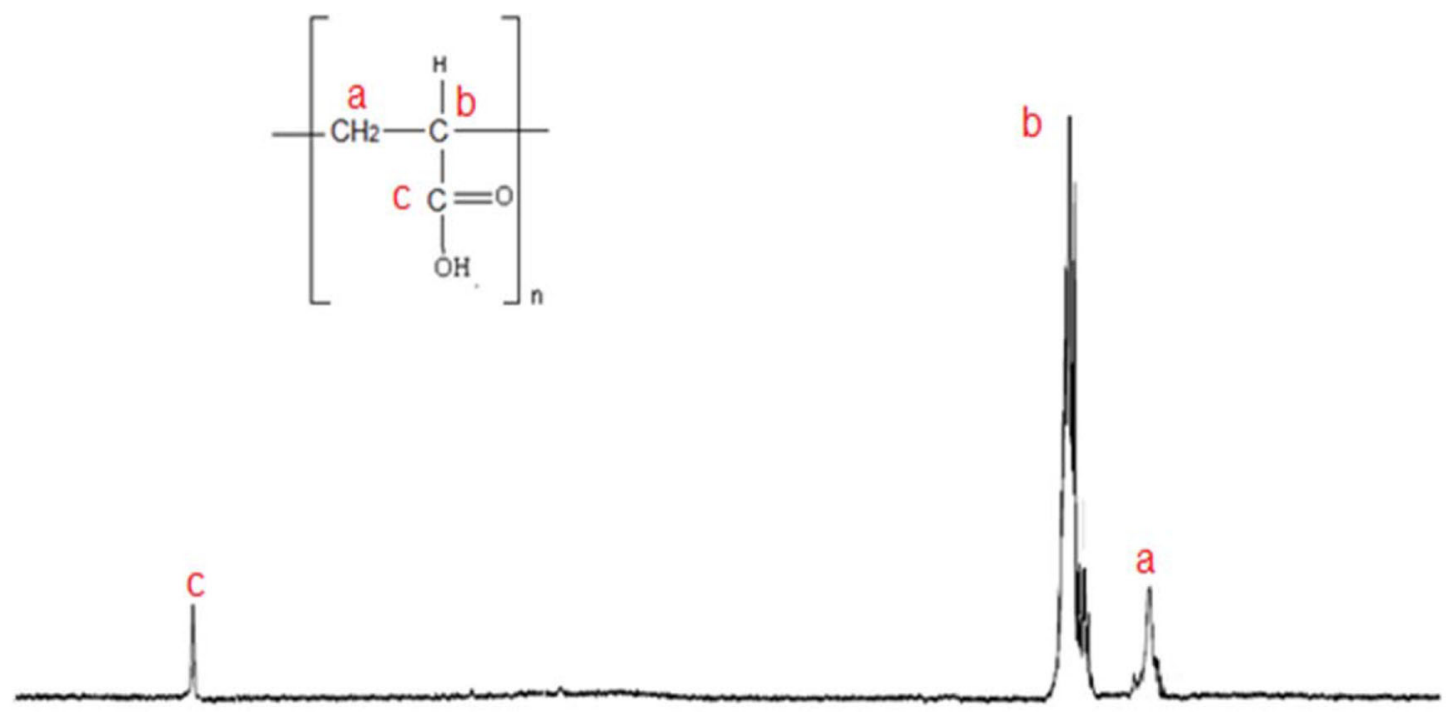

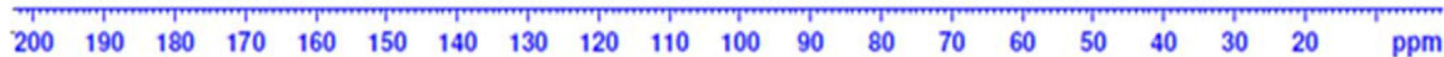
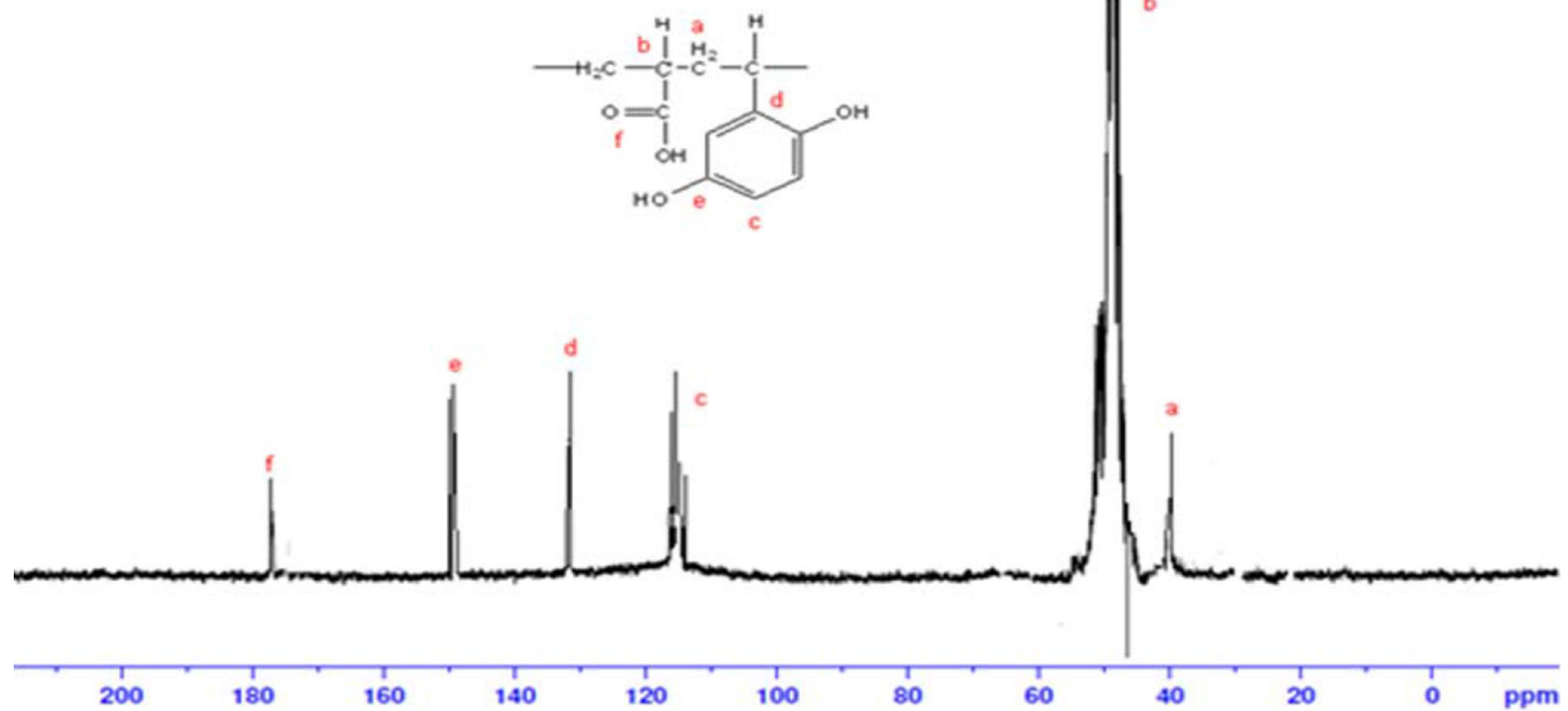

Fig. $3{ }^{13} \mathrm{C}$ NMR spectra of PAA and HQ-PAA. $\mathrm{CD}_{3} \mathrm{OD}$ as a solvent

occurrence in the course of the modification reaction. This phenomenon was also observed earlier upon the reaction of PAA and PAAm (polyacrylamide) with 2,5-dihydroxybenzoquinone (DHBQ) under identical conditions [5, 13]. Neira et al. [28] reported the degradation of PAA when grafted onto cellulose using Fenton's reagent (Fe(II)/ $\mathrm{H}_{2} \mathrm{O}_{2}$ ), a redox system.

The glass transition temperature for the modified PAA $\left(T_{\mathrm{g}}=135.8^{\circ} \mathrm{C}\right.$ ) was lower than that for the pristine PAA $\left(151.26{ }^{\circ} \mathrm{C}\right.$ ), as noticed in Fig. 7 (Table 1). The lower $T_{\mathrm{g}}$ measured for HQ-PAA can be due to the relatively low molecular weight obtained. The DSC thermogram of HQPAA revealed another thermal transition at $212.8^{\circ} \mathrm{C}$ which could be taken as the melting point $T_{\mathrm{m}}$ of the modified PAA. The small area at this endothermal peak would hint at the degree of crystallinity ensued during such functionalization as discussed above.

Thermogravimetric analyses of PAA and HQ-PAA are presented in Fig. 8. A two-step degradation for PAA can be noticed; an intense degradation of PAA (about $71 \%$ weight loss) occurred between 250 and $300{ }^{\circ} \mathrm{C}$, followed by a weaker one between 360 and $460{ }^{\circ} \mathrm{C}$ (about $25 \%$ 
Fig. 4 XRD spectra of PAA and HQ-PAA ([BQ]/ $[\mathrm{AA}]=1.25)$

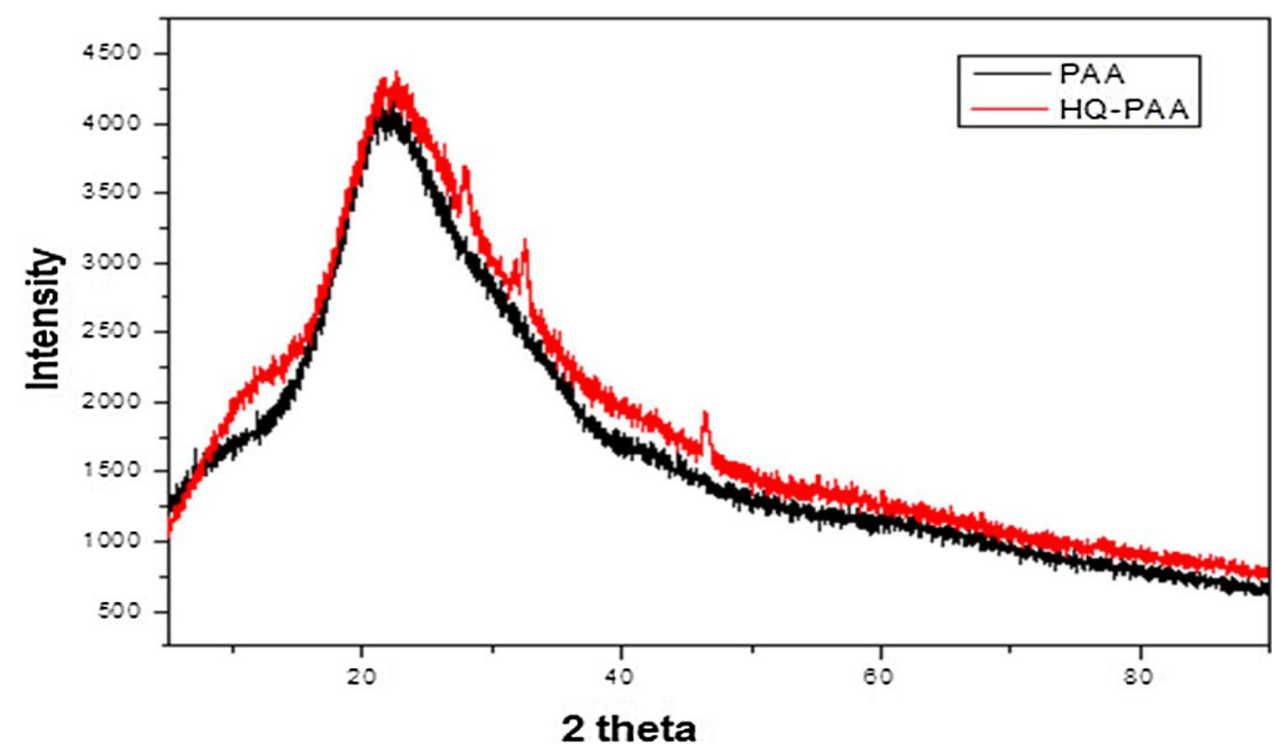

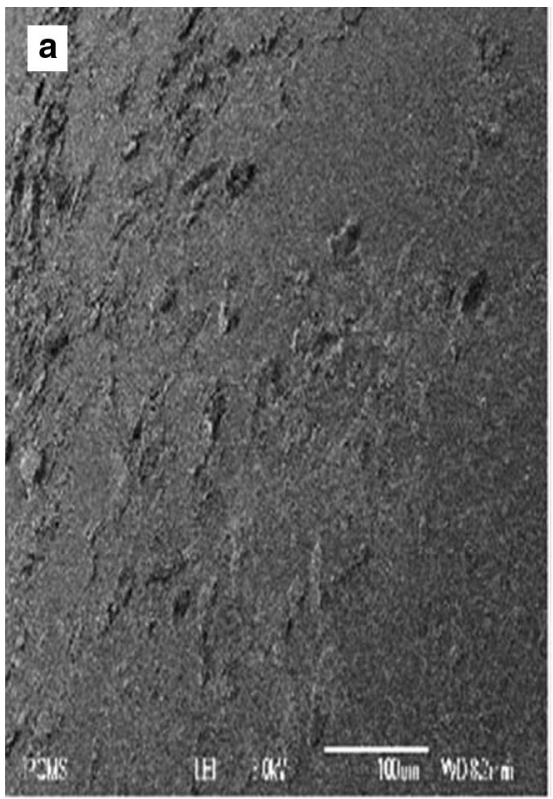
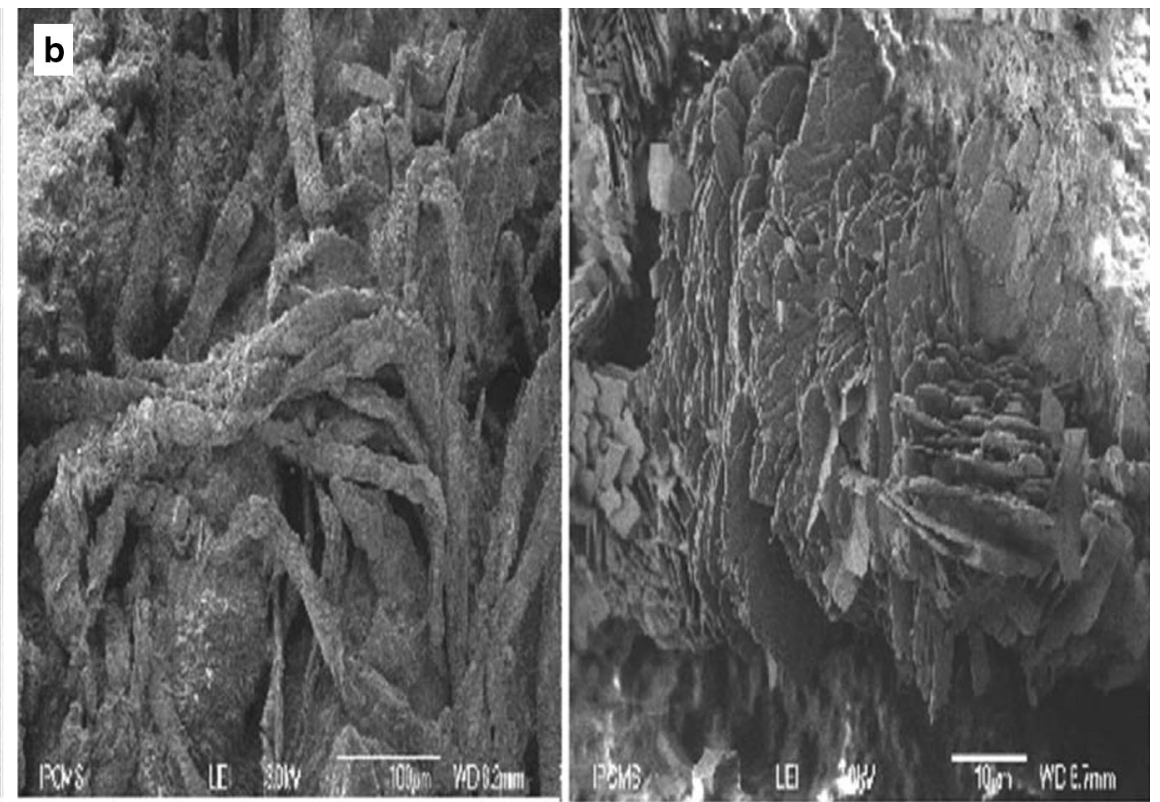

Fig. 5 SEM images: a PAA, $\times 230$; b HQ-PAA, $\times 230$; c HQ-PAA, $\times 1500$

weight loss). However, a three-stage degradation of $\mathbf{H Q -}$ PAA was detected; the first stage $(10 \%)$ started at $100{ }^{\circ} \mathrm{C}$ and continued up to $160{ }^{\circ} \mathrm{C}$, the second (35\% weight loss) between 200 and $280{ }^{\circ} \mathrm{C}$, and the third (31\% weight loss) began at $360{ }^{\circ} \mathrm{C}$ and continued to $440{ }^{\circ} \mathrm{C}$. Three maximum loss rates manifested at 230,403 , and $131{ }^{\circ} \mathrm{C}$; the first loss rate may be attributed to the decarboxylation or anhydride formation, and the second and the third loss rates may be assigned to the degradation of HQ moieties. The results obtained by TGA for HQ-PAA and PAA were consistent with those revealed by DSC measurements.

\section{Effect of $[B Q] /[$ monomer unit] ratio}

The effect of [modifier]/[monomer unit] molar ratio, [BQ]/ [AA], on substitution extent of the modification of PAA was assessed at 70-80 ${ }^{\circ} \mathrm{C}$ and for two reaction times, 3 and $6 \mathrm{~h}$. Such an effect is illustrated in Fig. 9. The degree of modification was estimated by UV absorbance of the HQPAA using a calibration curve that was established by measuring the absorbance of dilute hydroquinone solutions at $\lambda_{\text {max }}=288 \mathrm{~nm}$; as can be noticed in the figure, the variations of modification degree increased with increasing 
Fig. 6 GPC elution profiles for PAA and HQ-PAA ([BQ]/ $[\mathrm{AA}])=1.25$ )

Table 1 Molecular weights of PAA, HQ-PAA, and their $T_{\mathrm{g}}$

Fig. 7 DSC thermograms of PAA and HQ-PAA ([BQ]/ $[\mathrm{AA}])=1.25$. Scanning rate: $5{ }^{\circ} \mathrm{C} / \mathrm{min} ; \mathrm{N}_{2}$ atmosphere

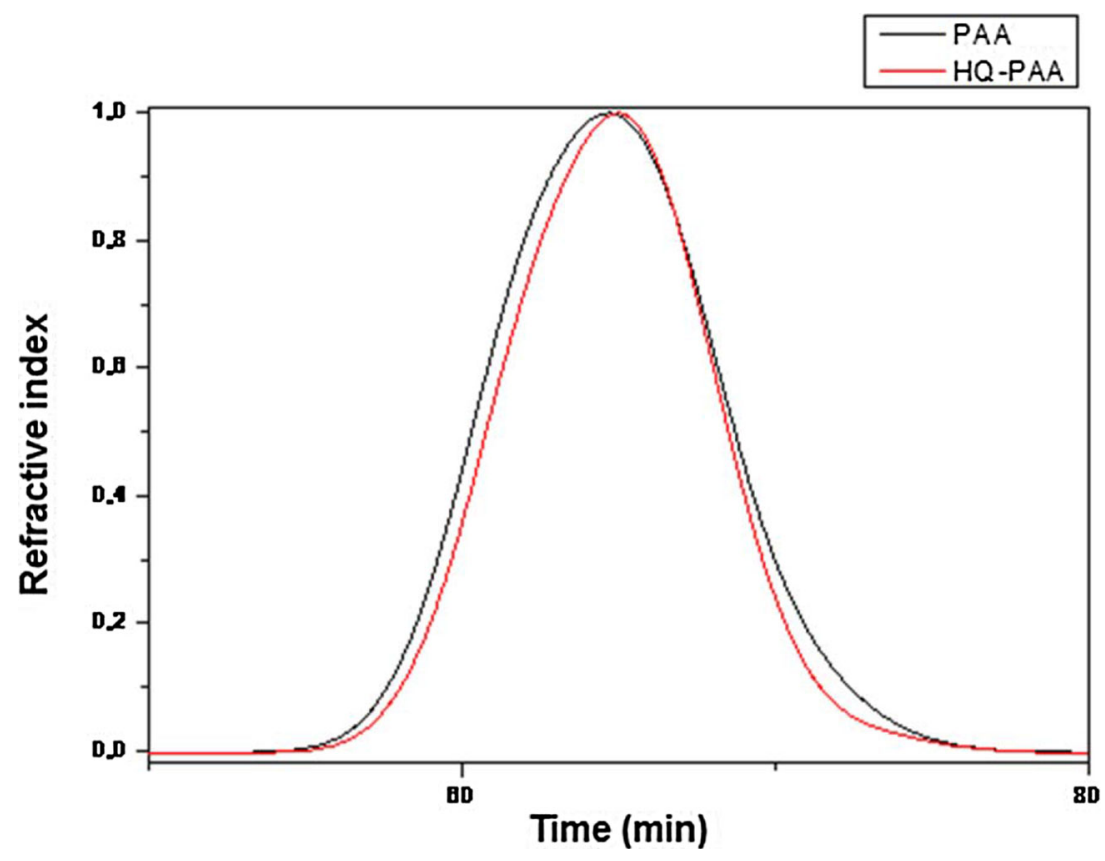

\begin{tabular}{lllll}
\hline & $M_{\mathrm{w}} \times 10^{-6}\left(\mathrm{~g} \mathrm{~mol}^{-1}\right)$ & $M_{\mathrm{n}} \times 10^{-6}\left(\mathrm{~g} \mathrm{~mol}^{-1}\right)$ & $M_{\mathrm{w}} / M_{\mathrm{n}}$ & $T_{\mathrm{g}}\left({ }^{\circ} \mathrm{C}\right)$ \\
\hline PAA & 2.54 & 1.45 & 1.75 & $151.26(142)^{\mathrm{b}}$ \\
HQ-PAA $^{\mathrm{a}}$ & 2.38 & 1.51 & 1.58 & 135.8 \\
\hline
\end{tabular}

${ }^{a}$ Modified PAA using $[\mathrm{BQ}] /[\mathrm{AA}]=1.25$

b Reference [10]

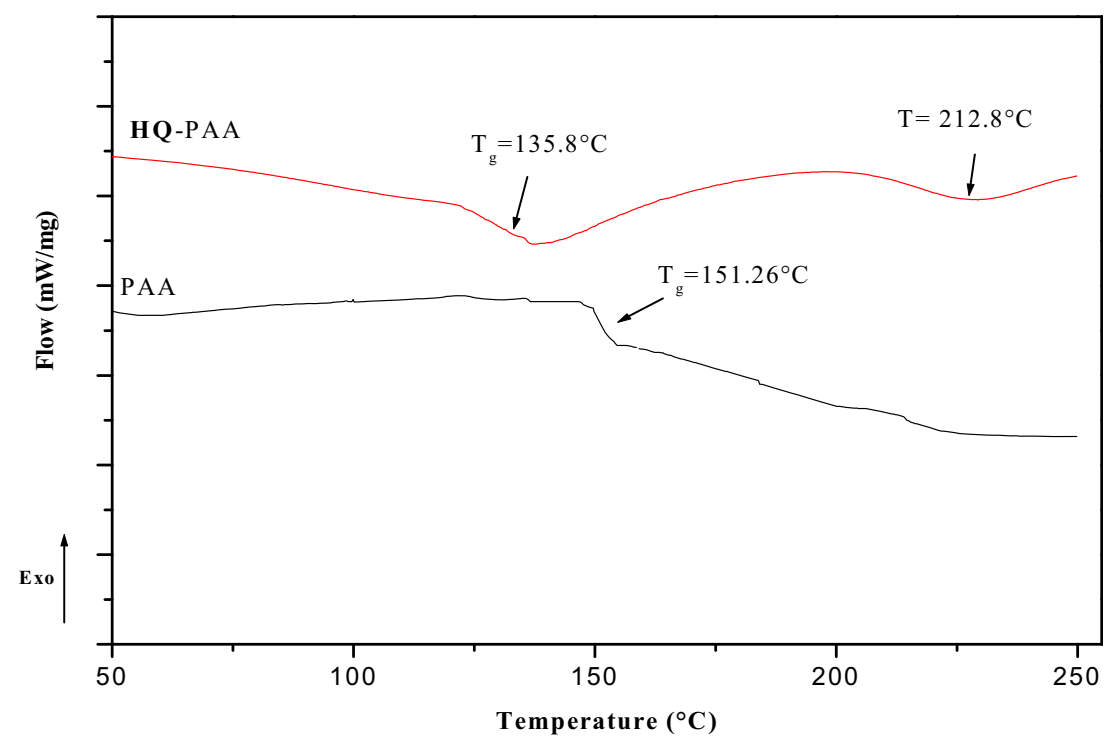

$[\mathrm{BQ}] /[\mathrm{AA}]$ and high substitution extents (29-32 \%) were gained with a ratio higher than 1 . In addition, prolonging the reaction time from 3 to $6 \mathrm{~h}$ in both the cases did not improve significantly the substitution extent.

\section{Effect of reaction time}

The impact of reaction time on the modification extent of PAA for a $[\mathrm{BQ}] /[\mathrm{AA}]$ ratio of 1.25 is presented in Fig. 10. 


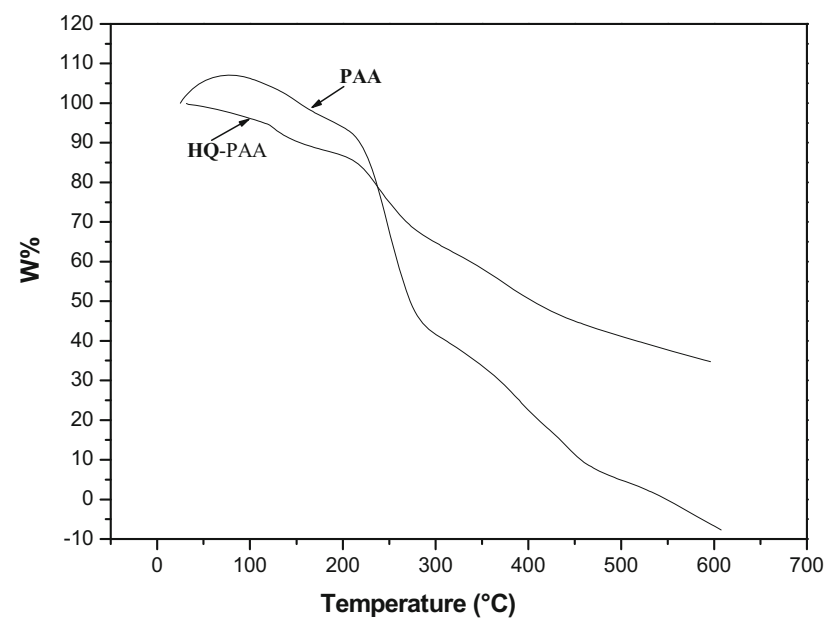

Fig. 8 TGA thermograms of PAA and HQ-PAA ([BQ]/ $[\mathrm{AA}])=1.25$. Heating rate: $10^{\circ} \mathrm{C} / \mathrm{min} ; \mathrm{N}_{2}$ atmosphere

The substitution extent increased with increasing reaction time, and optimal substitutions were reached at a time of $5 \mathrm{~h}$ and leveled off at $32 \%$ beyond this time.

\section{Metallic adsorption-desorption study}

PAA and HQ-PAA adsorbents were set by cross-linking their corresponding soluble polymers applying the oxidative decarboxylation conditions of Minisci as traced in Eqs. 4 and 5. The HQ-PAA used in the adsorption of the metallic ions was the one modified with a molar ratio [BQ]/ [AA] of 1.25 that corresponds to $32 \%$ degree of substitution. The effects of $\mathrm{pH}$, time, ionic strength, temperature, adsorbent mass, and initial concentration of copper, on the
$\mathrm{Cu}(\mathrm{II})$ adsorption capacities of the PAA and HQ-PAA resins, were assessed, and the results are illustrated in Figs. 11, 12, 13, 14, and 15, 16 and compiled in Tables 2, 3,4 , and 5. A tentative structure of the HQ-PAA adsorbent/ $\mathrm{Cu}^{2+}$ complex at $\mathrm{pH}$ of 5.4 is pictured in Fig. 11 .

It can be seen that the adsorption capacities of the PAA and HQ-PAA resins with respect to copper (II) increased with increasing $\mathrm{pH}$ and time, as shown in Figs. 12 and 13. They remained constant beyond a time of about $3 \mathrm{~h}$. At $\mathrm{pH}$ values lower than 3 , the sorption rate increased by raising the $\mathrm{pH}$, but at higher values, the rate was independent on $\mathrm{pH}$. The impact of this parameter on the removal of metallic ions from solutions is clear, because it affects the surface charge of sorbent. A higher $\mathrm{pH}$ would favor the tendency of negative charge formation on the sorbent, leading to an increase in the electrostatic attraction between the positively charged metallic ions and the negatively charged sorbent, thus a greater metallic sorption. The capacity exchanges were found to be 3.58 and $17.17 \mathrm{mg} \mathrm{g}^{-1}$, respectively, at an optimal $\mathrm{pH}$ of 5.4 and a time of $3 \mathrm{~h}$. Hence, HQPAA resin was nearly five times more effective than PAA resin in terms of copper (II) adsorption. This finding can be attributed to the grafted HQ moieties on the PAA matrix. The experiment was limited to the indicated $\mathrm{pH}$ values, because copper hydroxide would precipitate at $\mathrm{pH}$ values higher than 5.4, and would interfere with the actual results. On the other hand, the removal efficiency of metallic ion was found unexpectedly unaffected by increasing the ion strength of the solution, as shown in Fig. 14 and Table 2. In fact, the addition of $\mathrm{NaNO}_{3}$, as an electrolyte, at varying
Fig. 9 Plot of the variation of substitution degree of PAA, $S(\%)$, as a function of [BQ]/ [AA] molar ratio.

Temperature $=70-80{ }^{\circ} \mathrm{C}$

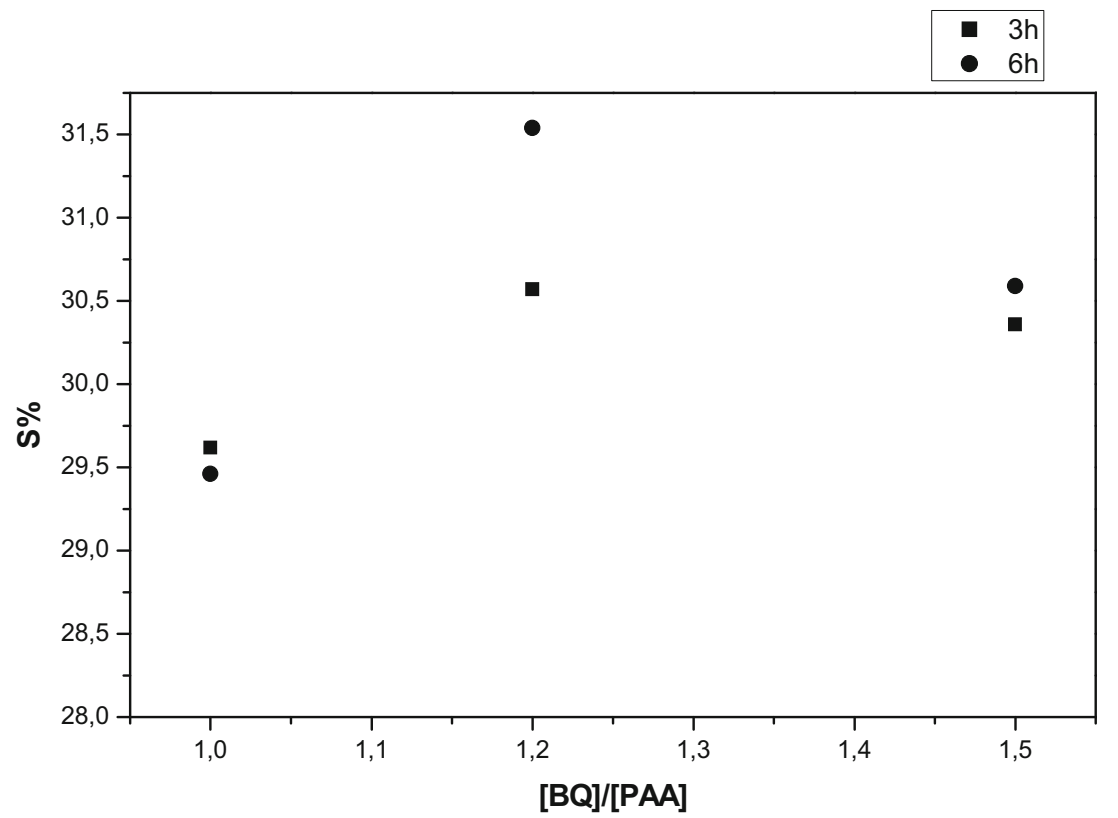


Fig. 10 Variation of the substitution degree of PAA, $S(\%)$, as a function of time. $T=70-80{ }^{\circ} \mathrm{C}$

Fig. 11 Proposed structure of the copper (II)/HQ-PAA complex at $\mathrm{pH} 5.4$

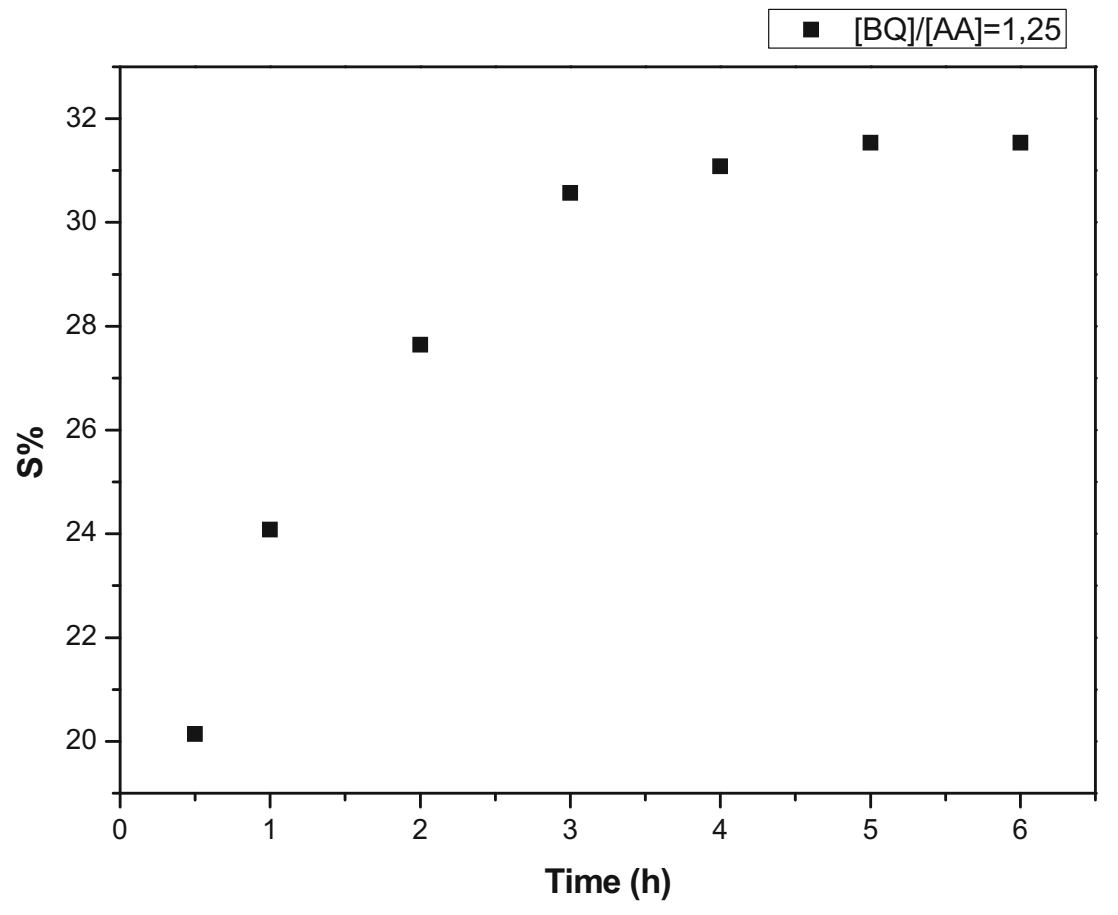

concentrations neither improved nor declined the sorption property. The present results are in good agreement with those reported [29, 30].

The effect of temperature on the adsorption capacities of the resins is shown in Fig. 15 and Table 3, demonstrating that the higher the temperature, the greater the adsorption capacity; at optimal $\mathrm{pH}(5.4)$ and time (3 h), the exchange capacities were 5.5 and $20.25 \mathrm{mg} \mathrm{g}^{-1}$ at a temperature of $45^{\circ} \mathrm{C}$ for PAA and HQ-PAA resins, respectively. In these conditions, the $\mathrm{COOH}$ groups in the adsorbing resins are in the form of carboxylate ions, because the working $\mathrm{pH}(5.4)$ is higher than $\mathrm{pK}_{\mathrm{a}}$ of PAA (4.7), and the phenolic $\mathrm{OH}$ groups in the HQ-PAA resin are not ionized due to their higher $\mathrm{pK}_{\mathrm{a}}(\sim 9.4)$; the carboxylate ions would complex metallic ions more favorably than the catechol hydroxyl groups.

Figures 16 and 17 picture the effects of the adsorbing resin mass and the initial copper concentration on the 
Fig. 12 Variations of adsorption capacity $Q_{\mathrm{t}}$ of PAA resin for copper (II) as a function of time and $\mathrm{pH}$. $V=50 \mathrm{~mL}, C_{0}=50 \mathrm{mg} / \mathrm{L}$,

$W=0.1 \mathrm{~g},\left[\mathrm{NaNO}_{3}\right]=0$, and $T=30^{\circ} \mathrm{C}$
Fig. 13 Variations of adsorption capacity $Q_{\mathrm{t}}$ of $\mathbf{H Q}$ $\mathrm{PAA}$ resin $([\mathrm{BQ}] /[\mathrm{AA}])=1.25$ for copper (II) as a function of time and $\mathrm{pH} . V=50 \mathrm{~mL}$, $C_{0}=50 \mathrm{mg} / \mathrm{L}, W=0.1 \mathrm{~g}$, $\left[\mathrm{NaNO}_{3}\right]=0$, and $T=30{ }^{\circ} \mathrm{C}$
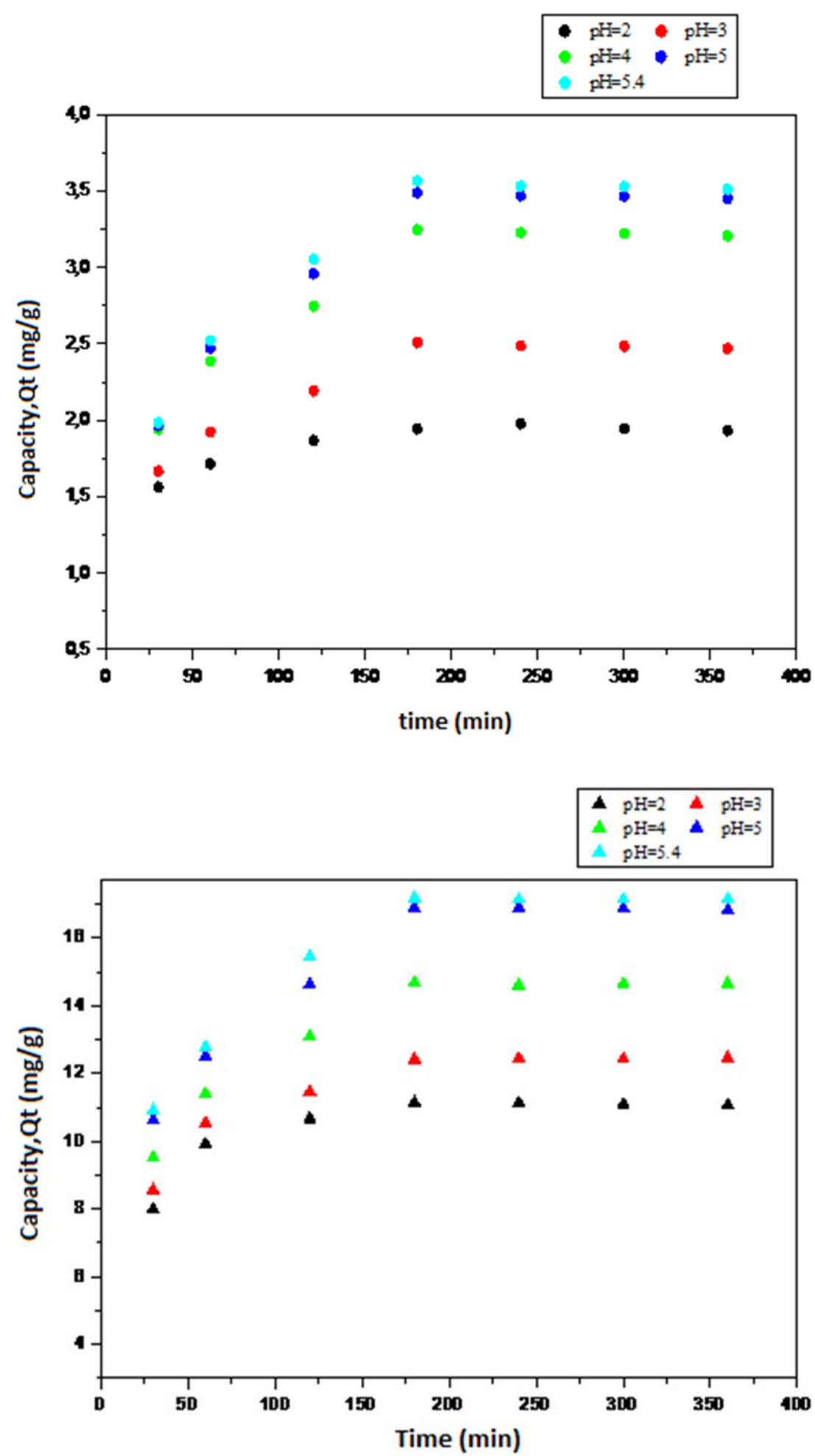

sorption of copper ion $\mathrm{Cu}(\mathrm{II})$, and the results are compiled in Tables 4 and 5. As can be noticed in Table 4, about $94 \%$ enhancement of the exchange capacity of PAA resin was observed at optimal conditions by increasing the mass of the sorbent by twofold, but only $22 \%$ enhancement for
HQ-PAA resin was found. Raising the initial concentration of copper nitrate improved the metal ion uptakes of the resins (Table 5) with nearly the same extents as with the variation of sorbent mass. These results are in tune with the published reports [31, 32]. 
Fig. 14 Variations of adsorption capacity $Q_{\mathrm{t}}$ of $\mathbf{H Q -}$ $\mathrm{PAA} \operatorname{resin}([\mathrm{BQ}] /[\mathrm{AA}])=1.25$ for copper (II) as a function of time and $\left[\mathrm{NaNO}_{3}\right] . V=50 \mathrm{~mL}$, $C_{0}=50 \mathrm{mg} / \mathrm{L}, W=0.1 \mathrm{~g}, \mathrm{pH}$ 5.4, and $T=30^{\circ} \mathrm{C}$
Fig. 15 Variations of adsorption capacity $Q_{\mathrm{t}}$ of $\mathbf{H Q -}$ $\operatorname{PAA}([\mathrm{BQ}] /[\mathrm{AA}])=1.25$ and PAA resins for copper (II) as a function of time and temperature. $V=50 \mathrm{~mL}$, $C_{0}=50 \mathrm{mg} / \mathrm{L}, W=0.1 \mathrm{~g}$, $\left[\mathrm{NaNO}_{3}\right]=0, T=30^{\circ} \mathrm{C}$, and $\mathrm{pH} 5.4$
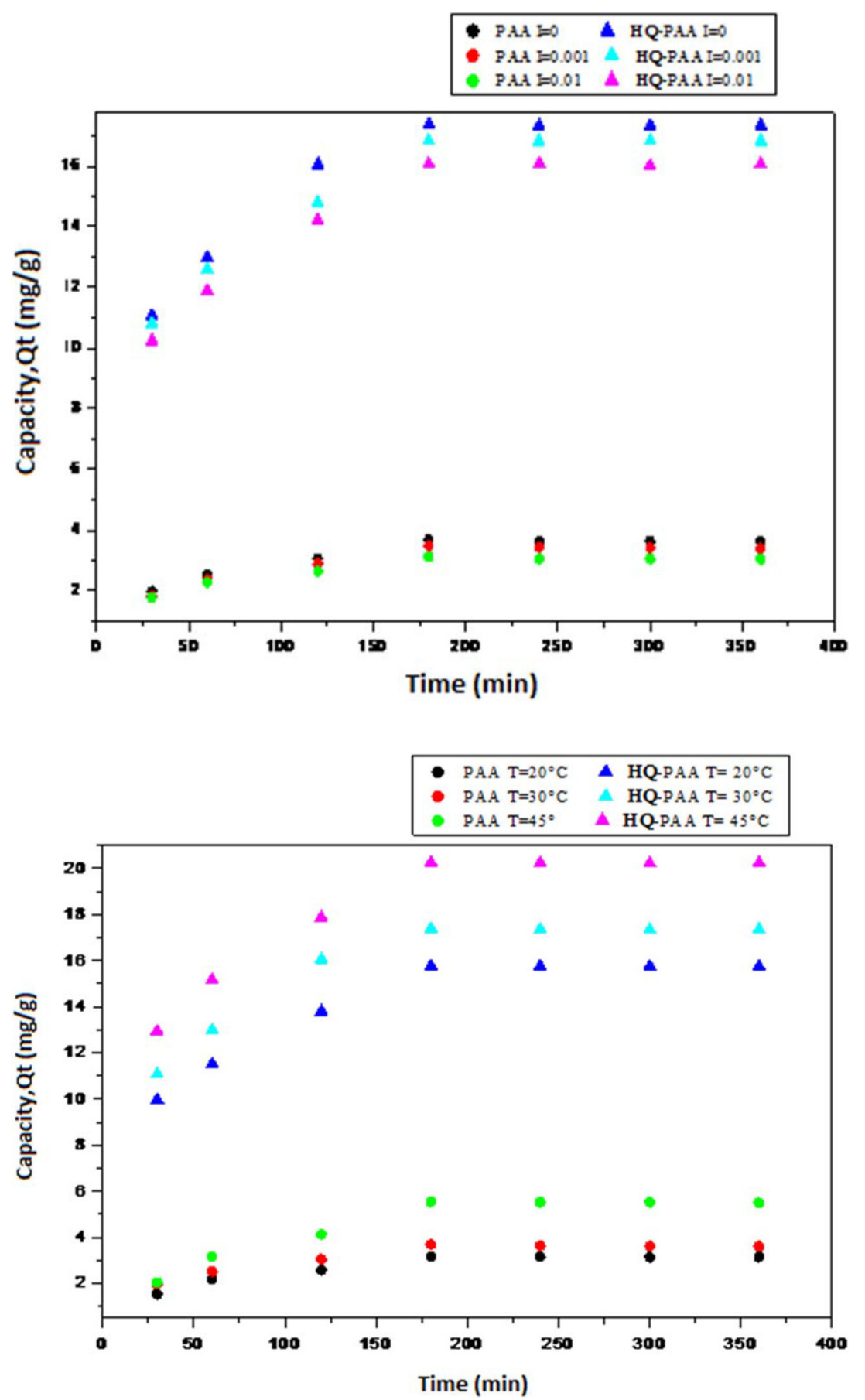

The adsorption of lead (II) and cadmium (II) by the resins was conducted and compared with that of copper (II) under the same optimal conditions. The adsorption capacities of the resins towards these metal ions are depicted in Fig. 18 and gathered in Table 6. Maximum adsorptions of $\mathrm{Pb}$ (II) and $\mathrm{Cd}(\mathrm{II})$ by PAA resin were 7.04 and $2.88 \mathrm{mg} \mathrm{g}^{-1}$, and were 20.84 and $12.69 \mathrm{mg} \mathrm{g}^{-1}$ by HQ-PAA resin. Under the actual experimental conditions, the exchange capacity is in this order: $\mathrm{Pb}(\mathrm{II})>\mathrm{Cu}(\mathrm{II})>\mathrm{Cd}(\mathrm{II})$. The adsorption capacity of the adsorbent is more for lead when compared to other metals, because the stability constants of complexes of lead with carboxylates and phenols are greater than those for other metals [33, 34]. The cross-linked poly(acrylic acid-co-Kryptofix-22-DM) [36], the tetrahydroxybenzenefunctionalized PAA [5], and the tetrahydroxybenzenefunctionalized PAAm [14] showed the same order of sorption capacity. Overall, our results are within with those reported in the literature (Table 7). 
Fig. 16 Variations of adsorption capacity $Q_{\mathrm{t}}$ of $\mathbf{H Q -}$ $\mathrm{PAA} \operatorname{resin}([\mathrm{BQ}] /[\mathrm{AA}])=1.25$ for copper (II) as a function of adsorbent mass. $V=50 \mathrm{ml}$, $C_{0}=50 \mathrm{mg} / \mathrm{L}, \mathrm{pH} 5.4$, and $T=30{ }^{\circ} \mathrm{C}$

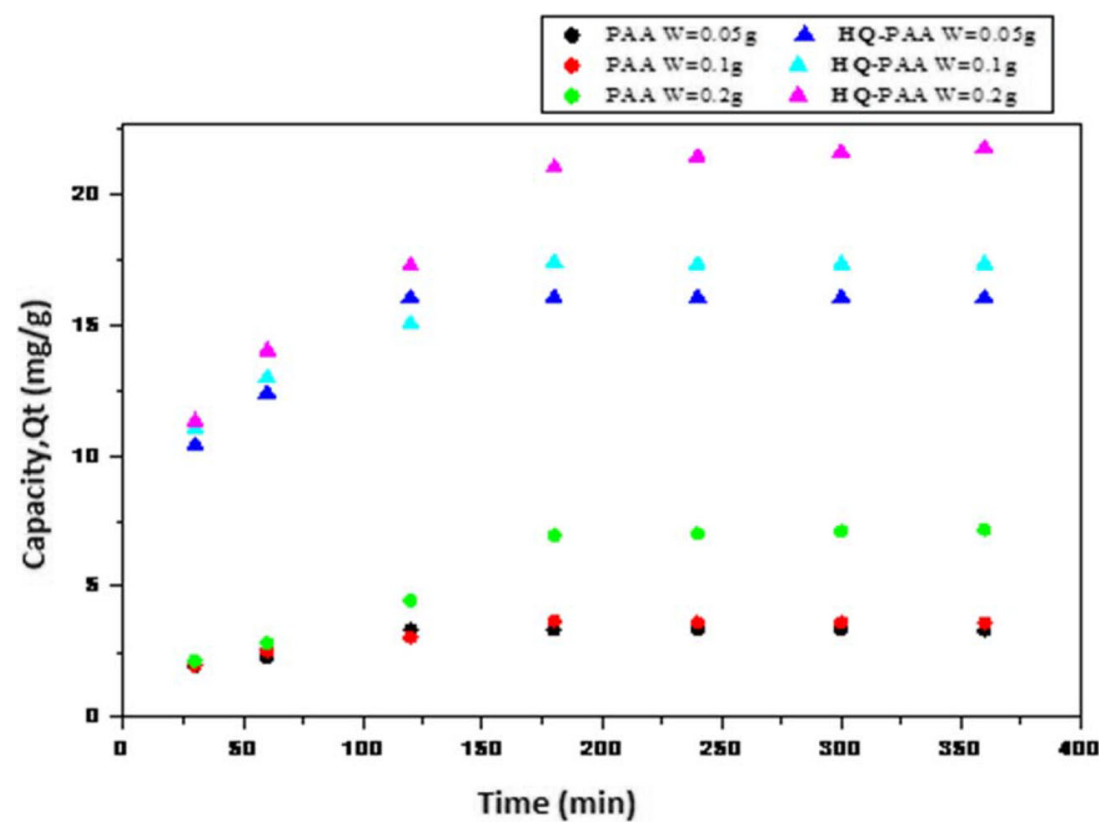

Table 2 Sorption of copper ion at different $\left[\mathrm{NaNO}_{3}\right]$

\begin{tabular}{lll}
\hline$\left[\mathrm{NaNO}_{3}\right]$ & \multicolumn{2}{l}{ Sorption of $\mathrm{Cu}^{2+}\left(\mathrm{mg} \mathrm{g}^{-1}\right)$} \\
\cline { 2 - 3 } & PAA & HQ-PAA \\
\hline 0 & 3.58 & 17.17 \\
0.001 & 3.46 & 16.81 \\
0.01 & 3.11 & 16.01 \\
\hline
\end{tabular}

$\mathrm{pH} 5.4 ; t=3 \mathrm{~h} ; C_{0}=50 \mathrm{mg} / \mathrm{L} ; T=30^{\circ} \mathrm{C} ; W=0.1 \mathrm{~g}$

${ }^{\mathrm{a}}$ Modified PAA using [BQ]/[AA] $=1.25$

Table 3 Sorption of copper ion at different temperatures

\begin{tabular}{lll}
\hline Temperature $\left({ }^{\circ} \mathrm{C}\right)$ & \multicolumn{2}{l}{ Sorption of $\mathrm{Cu}^{2+}\left(\mathrm{mg} \mathrm{g}^{-1}\right)$} \\
\cline { 2 - 3 } & PAA & HQ-PAA \\
\hline 20 & 3.17 & 15.76 \\
30 & 3.58 & 17.17 \\
45 & 5.54 & 20.25 \\
\hline
\end{tabular}

$\mathrm{pH} 5.4 ; t=3 \mathrm{~h} ; \quad W=0.1 \mathrm{~g} ;\left[\mathrm{NaNO}_{3}\right]=0 \mathrm{~g} / \mathrm{L} ; . \quad C_{0}=50 \mathrm{mg} / \mathrm{L} ;$ $T=30{ }^{\circ} \mathrm{C}$

${ }^{\mathrm{a}}$ Modified PAA using $[\mathrm{BQ}] /[\mathrm{AA}]=1.25$

\section{Adsorption kinetics}

Pseudo-first-order model (Lagergren equation) The pseudo-first-order kinetic is expressed, as shown in Eq. 8 [37]:

$\log \left(Q_{\mathrm{e}}-Q_{t}\right)=\log Q_{\mathrm{e}}-\frac{k_{1} t}{2.303}$

where
Table 4 Sorption of copper ion at different sorbent masses

\begin{tabular}{lll}
\hline Sorbent mass $(\mathrm{g}), W$ & \multicolumn{2}{l}{ Sorption of $\mathrm{Cu}^{2+}\left(\mathrm{mg} \mathrm{g}^{-1}\right)$} \\
\cline { 2 - 3 } & PAA & HQ-PAA \\
\hline 0.05 & 3.32 & 15.06 \\
0.10 & 3.58 & 17.17 \\
0.20 & 6.94 & 21.03 \\
\hline
\end{tabular}

$\mathrm{pH} 5.4 ; t=3 \mathrm{~h} ; C_{0}=50 \mathrm{mg} / \mathrm{L} ;\left[\mathrm{NaNO}_{3}\right]=0 \mathrm{~g} / \mathrm{L}$

${ }^{\mathrm{a}}$ Modified PAA using $[\mathrm{BQ}] /[\mathrm{AA}]=1.25$

$k_{1}$ is the pseudo-first-order rate constant $\left(\min ^{-1}\right)$,

$Q_{\mathrm{e}}$ is the adsorption capacity of the adsorbent $\left(\mathrm{mg} \mathrm{g}^{-1}\right)$, $Q_{t}$ is the amount of $\mathrm{Cu}$ ion adsorbed at time $t\left(\mathrm{mg} \mathrm{g}^{-1}\right)$. where $k_{1}$ is computed from the slope of the plot of $\ln \left(Q_{\mathrm{e}}-Q_{t}\right)$ versus $t$ (Fig. 19).

Pseudo-second-order model (Ho-McKay equation) The pseudo-second-order kinetic is expressed as shown in Eq. 9 [38].

${ }^{t} / Q_{\mathrm{t}}=t / Q_{\mathrm{e}}+1 / k_{2} Q_{\mathrm{e}}^{2}$

where $k_{2}$ is the pseudo-second-order rate constant $\left(\mathrm{g} \mathrm{mg}^{-1} \mathrm{~min}^{-1}\right)$ and computed from the slope of the plot of $t / Q_{t}$ versus $t$ (Fig. 20).

The results of the applied models to the copper (II) adsorption by PAA and HQ-PAA are illustrated in Figs. 19 and 20 and compiled in Table 8 . As can be noticed in Table 8 , the experimental $Q_{\mathrm{e}}$ values are so distant from the calculated ones and the correlation coefficients are low, suggesting that this adsorption does not obey a pseudo-first kinetic model; the graphs in Fig. 19 are not straight lines, 
Table 5 Sorption of copper ion at different $\mathrm{Cu}^{2+}$ concentrations

\begin{tabular}{lll}
\hline Initial concentration of copper $(\mathrm{II}), C_{0}(\mathrm{mg} / \mathrm{L})$ & \multicolumn{2}{l}{ Sorption of $\mathrm{Cu}^{2+}\left(\mathrm{mg} \mathrm{g}^{-1}\right)$} \\
\cline { 2 - 3 } & PAA & HQ-PAA \\
\hline 10 & 3.23 & 15.89 \\
50 & 3.58 & 17.17 \\
100 & 6.77 & 20.84 \\
\hline
\end{tabular}

pH 5.4; $t=3 \mathrm{~h} ; W=0.1 \mathrm{~g} ;\left[\mathrm{NaNO}_{3}\right]=0 \mathrm{~g} / \mathrm{L}$

a Modified PAA using $[\mathrm{BQ}] /[\mathrm{AA}]=1.25$
Fig. 17 Variations of adsorption capacity $Q_{\mathrm{t}}$ of $\mathbf{H Q}$ PAA resin $([\mathrm{BQ}] /[\mathrm{AA}])=1.25$ for copper (II) as a function of $\mathrm{Cu}$ (II) concentration.

$V=50 \mathrm{~mL}, \mathrm{pH} 5.4$,

$T=30{ }^{\circ} \mathrm{C}$, and $W=0.1 \mathrm{~g}$
Fig. 18 Variations of

adsorption capacities $Q_{\mathrm{t}}$ of $\mathbf{H Q}$ $\mathrm{PAA}([\mathrm{BQ}] /[\mathrm{AA}])=1.25$ and

PAA resins for copper (II), lead (II), and cadmium (II) as a function of time. $V=50 \mathrm{~mL}$, $C_{0}=50 \mathrm{mg} / \mathrm{L}, W=0.1 \mathrm{~g}$, $\left[\mathrm{NaNO}_{3}\right]=0, T=30{ }^{\circ} \mathrm{C}$, and pH 5.4
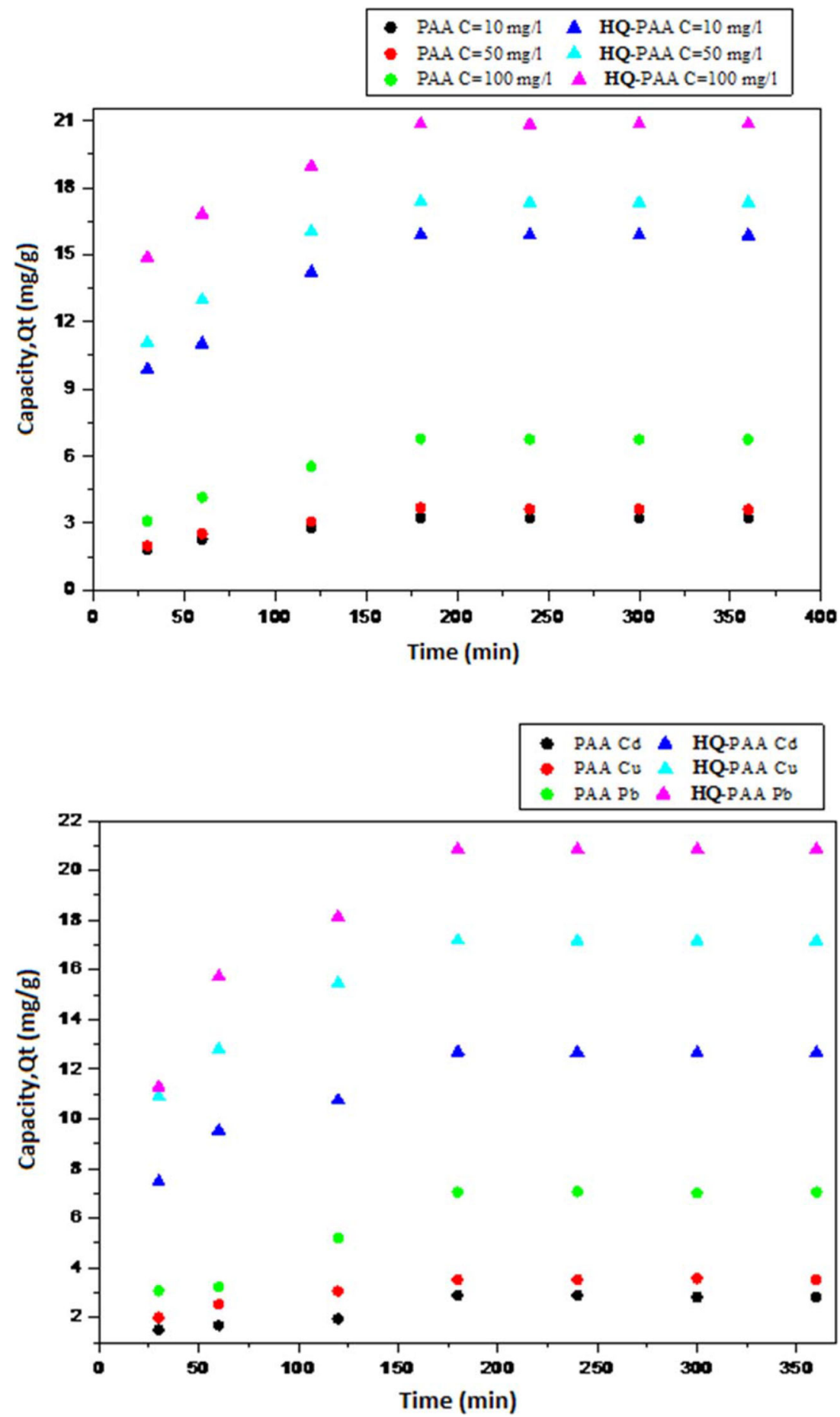
precluding the validity of Lagergren equation. However, the straight lines of the plot $t / Q_{t}$ versus time (Fig. 20) are indicative of the validity of Ho-McKay equation; indeed, the experimental $Q_{\mathrm{e}}$ values and the calculated ones are so close and the correlation coefficients are high as shown in Table 8, suggesting that the adsorption fits well a pseudosecond kinetic model.

\section{Adsorption isotherms}

Three adsorption isotherms models were examined for our data on the copper adsorption by PAA and HQ-PAA: Freundlich, Langumir, and Temkin.

Freundlich isotherm The linear form of the Freundlich equation is given in Eq. 10 [39]. For Freundlich isotherm, the ratio of sorbate adsorbed onto a given mass of adsorbent to the sorbate concentration in solution is not constant:

$\log Q_{\mathrm{e}}=\log K_{\mathrm{F}}+(1 / n) \log C_{\mathrm{e}}$

where

$Q_{\mathrm{e}}$ is the amount of solute adsorbed per-unit weight of adsorbent $\left(\mathrm{mg} \mathrm{g}^{-1}\right)$,

$K_{\mathrm{F}}$ is the Freundlich constant $\left(\mathrm{mg} \mathrm{g}^{-1}\right)$,

$C_{\mathrm{e}}$ is the equilibrium concentration of the solute in the bulk solution $\left(\mathrm{mg} \mathrm{L}^{-1}\right)$,

$1 / n$ is the heterogeneity factor indicating the adsorption intensity.

Table 6 Sorption of $\mathrm{Pb}^{2+}, \mathrm{Cu}^{2+}$, and $\mathrm{Cd}^{2+}$

\begin{tabular}{lll}
\hline Metallic ions & \multicolumn{2}{l}{ Sorption of ions $\left(\mathrm{mg} \mathrm{g}^{-1}\right)$} \\
\cline { 2 - 3 } & PAA & HQ-PAA \\
\hline $\mathrm{Pb}^{2+}$ & 7.04 & 20.84 \\
$\mathrm{Cu}^{2+}$ & 3.58 & 17.17 \\
$\mathrm{Cd}^{2+}$ & 2.88 & 12.69 \\
\hline
\end{tabular}

$\mathrm{pH} 5.4 ; t=3 \mathrm{~h}$; mass of resin $W=0.1 \mathrm{~g} ;\left[\mathrm{NaNO}_{3}\right]=0 \mathrm{~g} / \mathrm{L}$

${ }^{a}$ Modified PAA using $[\mathrm{BQ}] /[\mathrm{AA}]=1.25$
Langumir isotherm The linear form of Langmuir isotherm equation is given in Eq. 11 [40]. For the Langmuir isotherm, a monomolecular layer is supposedly formed, as the sorbate molecules are adsorbed without any interactions between them:

$C_{\mathrm{e} / Q_{\mathrm{e}}}=\left(1 / Q_{\max } K_{\mathrm{L}}\right)+\left(C_{\mathrm{e}} / Q_{\max }\right)$

where

$Q_{\max }$ is the maximum adsorption capacity of the adsorbent $\left(\mathrm{mg} \mathrm{g}^{-1}\right)$,

$K_{\mathrm{L}}$ is the Langmuir adsorption constant $\left(\mathrm{L} \mathrm{mg}^{-1}\right)$.

Temkin isotherm The linear form of the Temkin model equation is given in Eq. 12 [41]. For the Temkin model theory, the effect of the interactions between sorbate molecules on adsorption isotherms is taken into account, suggesting that the heat of adsorption of all the molecules in the layer would decrease linearly:

$Q_{\mathrm{e}}=B \ln A+B \ln C_{\mathrm{e}}$

where

$B=R T / b_{\mathrm{T}}, b_{\mathrm{T}}$ is the Temkin constant related to heat of sorption $\left(\mathrm{J} \mathrm{mol}^{-1}\right), R$ the gas constant $(8.314 \mathrm{~J} / \mathrm{mol} \mathrm{K})$, and $T$ is the absolute temperature,

$A$ is the Temkin isotherm constant $\left(\mathrm{L} \mathrm{g} \mathrm{g}^{-1}\right)$.

Data of the study of adsorption isotherms are illustrated in Figs. 21, 22, and 23, and Table 9. Based on the correlation coefficient $R^{2}$, none of the examined isotherm models would fit the adsorption data in the case of PAA; indeed, $R^{2}$ is poorly low and is in the range of $0.40-0.76$. However, in the case of HQ-PAA, the three models are more favorable; yet, the Langmuir model $\left(R^{2}=0.993\right)$ fits better than Temkin $\left(R^{2}=0.918\right)$ and Freundlich $\left(R^{2}=0.816\right)$. The fact that the present data obey better to Langmuir model can be assigned to the homogenous distribution of active sites on the HQ-PAA surface, as the Langmuir equation assumes a homogenous surface, where all the sites have equal adsorption energies. The Langmuir

Table 7 Adsorption capacity $\left(\mathrm{mg} \mathrm{g}^{-1}\right)$ of some polyhydroxybenzene-functionalized resins towards $\mathrm{Cu}^{2+}, \mathrm{Cd}^{2+}$, and $\mathrm{Pb}^{2+}$

\begin{tabular}{|c|c|c|c|c|c|}
\hline Polymer & Functionalizing group & $\begin{array}{l}\mathrm{Cu}^{2+} \\
\left(\mathrm{mg} \mathrm{g}^{-1}\right)\end{array}$ & $\begin{array}{l}\mathrm{Cd}^{2+} \\
\left(\mathrm{mg} \mathrm{g}^{-1}\right)\end{array}$ & $\begin{array}{l}\mathrm{Pb}^{2+} \\
\left(\mathrm{mg} \mathrm{g}^{-1}\right)\end{array}$ & References \\
\hline Cellulose & 1,2-Dihydroxybenzene (catechol) & 11.83 & 13.00 & 21.5 & {$[34]^{*}$} \\
\hline Amberlite XAD-4 & 1,2-Dihydroxybenzene (catechol) & 5.69 & 2.89 & / & {$[33]^{*}$} \\
\hline $\begin{array}{l}\text { Poly(vinylcatechol-co- } \\
\text { divinylbenzene }\end{array}$ & 1,2-Dihydroxybenzene (catechol) & 6.44 & 9.10 & / & {$[35]^{*}$} \\
\hline Poly(acrylic acid) & 1,2,4,5-Tetrahydroxybenzene (benzene-1,2,4,5-tetrol) & 19.54 & 14.90 & 22.16 & {$[5]$} \\
\hline Polyacrylamide & 1,2,4,5-Tetrahydroxybenzene (benzene-1,2,4,5-tetrol) & 18.87 & 17.58 & 20.74 & {$[13]$} \\
\hline Polyacrylamide & 1,4-Dihydroxybenzene (hydroquinone) & 5.01 & 4.36 & 5.91 & {$[14]$} \\
\hline Poly(acrylic acid) & 1,4-Dihydroxybenzene (hydroquinone) & 17.17 & 12.69 & 20.84 & Present work \\
\hline
\end{tabular}

* The mentioned values were computed from the results given in the corresponding articles 
Fig. 19 Pseudo-first-order model fit for the adsorption of $\mathrm{Cu}^{2+}$ at $\mathrm{pH}$ 5.4: a PAA; b HQPAA

Fig. 20 Pseudo-second-order model fit for the adsorption of $\mathrm{Cu}^{2+}$ at $\mathrm{pH}$ 5.4: a PAA; b HQPAA
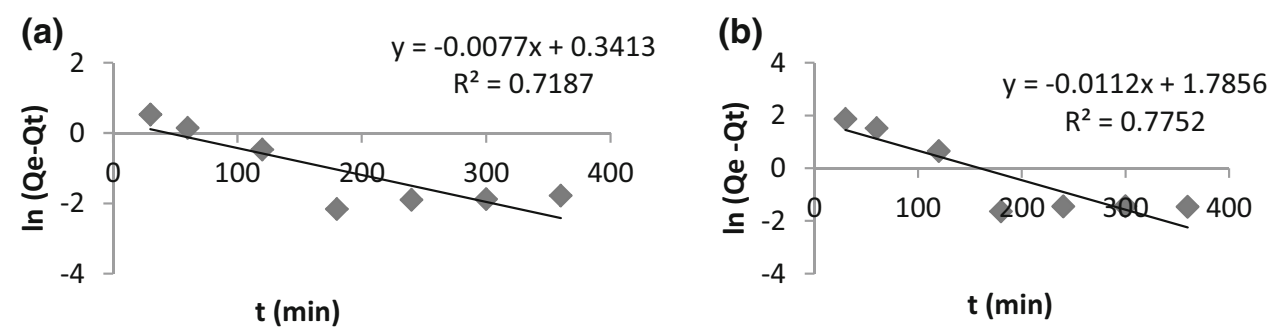
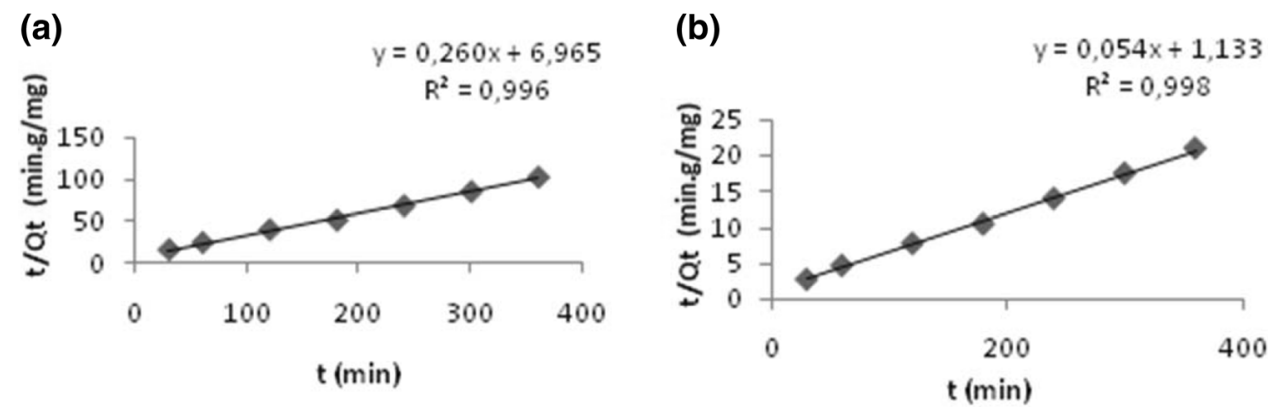

Table 8 Results of pseudo-first- and second-order models of $\mathrm{Cu}^{2+}$ adsorption

\begin{tabular}{|c|c|c|c|c|c|c|c|c|}
\hline \multirow[t]{2}{*}{ Sorbent } & \multicolumn{4}{|c|}{ Pseudo-first-order model } & \multicolumn{4}{|c|}{ Pseudo-second-order model } \\
\hline & $Q_{\mathrm{e} \exp }\left(\mathrm{mg} \mathrm{g}^{-1}\right)$ & $Q_{\mathrm{ecal}}\left(\mathrm{mg} \mathrm{g}^{-1}\right)$ & $k_{1}\left(\min ^{-1}\right)$ & $R^{2}$ & $Q_{\mathrm{e} \exp }\left(\mathrm{mg} \mathrm{g}^{-1}\right)$ & $Q_{\mathrm{ecal}}\left(\mathrm{mg} \mathrm{g}^{-1}\right)$ & $k_{2}\left(\mathrm{~g} \mathrm{mg}^{-1} \min ^{-1}\right)$ & $R^{2}$ \\
\hline PAA & 3.58 & 1.41 & 0.017 & 0.718 & 3.58 & 3.84 & 0.01 & 0.996 \\
\hline HQ-PAA & 17.17 & 5.96 & 0.025 & 0.775 & 17.17 & 18.34 & 0.002 & 0.998 \\
\hline
\end{tabular}

Fig. 21 Plots of Freundlich model for $\mathrm{Cu}^{2+}$ adsorption: a PAA; b HQ-PAA

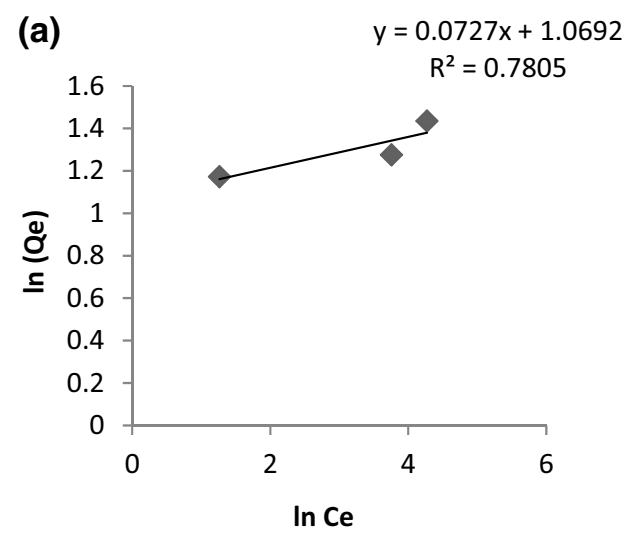

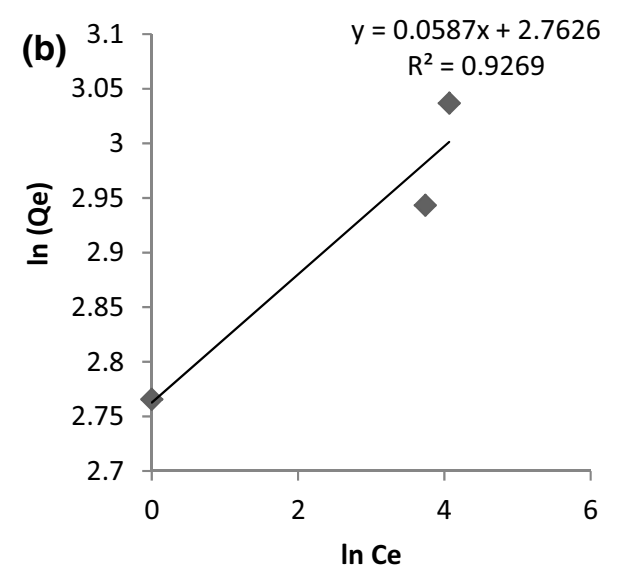

constant $K_{\mathrm{L}}$ is $0.181 \mathrm{~L} \mathrm{mg}^{-1}$, a value lower than 1 , indicating favorable adsorption. The maximum adsorption capacity of the HQ-PAA adsorbent, $Q_{\max }$, was measured to be $22.37 \mathrm{mg} \mathrm{g}^{-1}$. The Freundlich treatment of our data afforded $1 / n$ values greater than 1 , suggesting that the $\mathrm{Cu}^{2+}$ adsorption onto HQ-PAA adsorbent was unfavorable under the studied experimental conditions.

\section{Thermodynamic adsorption parameters}

To acquire an insight into the adsorption process of the $\mathrm{Cu}^{2+}$ ions and its distribution between the adsorbent and the aqueous medium, thermodynamic factors of the whole process are eagerly sought for; the Gibbs free energy of adsorption $\left(\Delta G^{0}\right)$, the entropy of adsorption $\left(\Delta S^{0}\right)$, and the 
Fig. 22 Plots of Langmuir model for $\mathrm{Cu}^{2+}$ adsorption: a PAA; b HQ-PAA
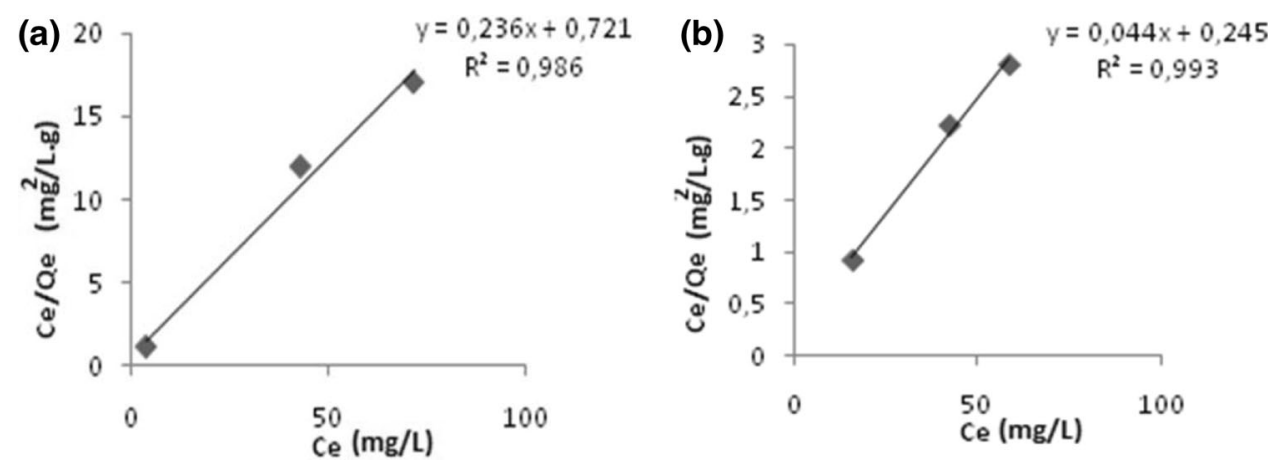

Fig. 23 Plots of Temkin model for $\mathrm{Cu}^{2+}$ adsorption: a PAA; b HQ-PAA
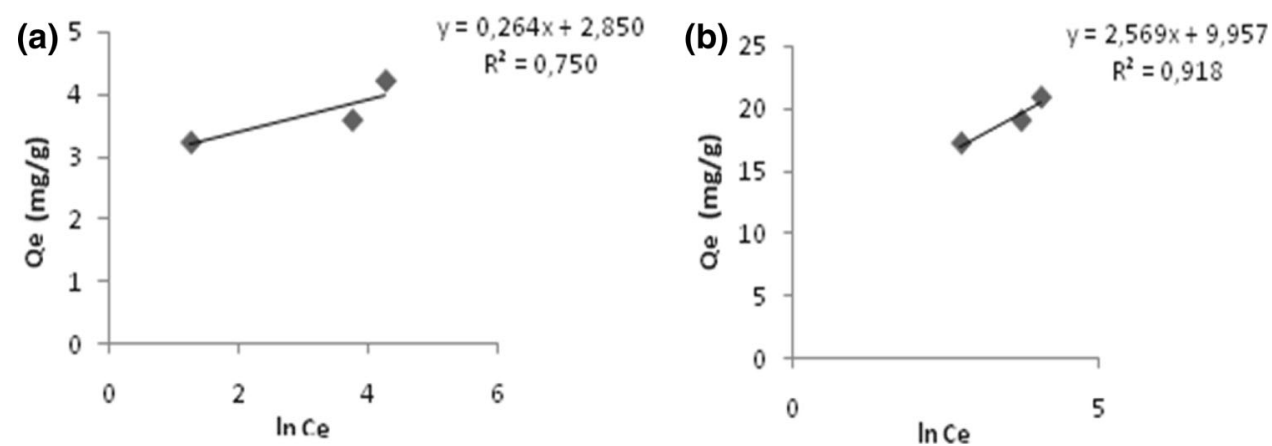

Table 9 Parameters of adsorption isotherm models for $\mathrm{Cu}^{2+} / \mathrm{PAA}$ and $\mathrm{Cu}^{2+} / \mathrm{HQ}-\mathrm{PAA}$ systems

\begin{tabular}{|c|c|c|c|c|c|c|c|c|c|}
\hline \multirow[t]{2}{*}{ Sorbent } & \multicolumn{3}{|c|}{ Freundlich } & \multicolumn{3}{|l|}{ Langmuir } & \multicolumn{3}{|l|}{ Temkin } \\
\hline & $1 / n$ & $K_{\mathrm{f}}\left(\mathrm{mg} \mathrm{g}^{-1}\right)$ & $R^{2}$ & $Q_{\max }\left(\mathrm{mg} \mathrm{g}^{-1}\right)$ & $K_{\mathrm{L}}\left(\mathrm{L} \mathrm{mg}^{-1}\right)$ & $R^{2}$ & $A\left(\mathrm{~L} \mathrm{~g}^{-1}\right)$ & $B\left(\mathrm{~J} \mathrm{~mol}^{-1}\right)$ & $R^{2}$ \\
\hline PAA & 6.514 & 2.512 & 0.480 & 6.157 & 0.067 & 0.762 & 19.995 & 0.690 & 0.407 \\
\hline HQ-PAA & 17.301 & 15.559 & 0.816 & 22.37 & 0.181 & 0.993 & 48.233 & 1.037 & 0.918 \\
\hline
\end{tabular}

Fig. 24 Plots of $\ln K_{\mathrm{d}}$ versus $1 /$ T. a PAA; b HQ-PAA

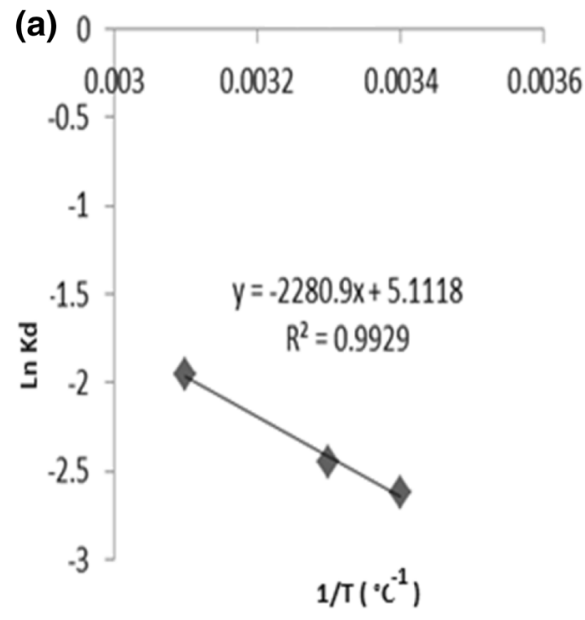

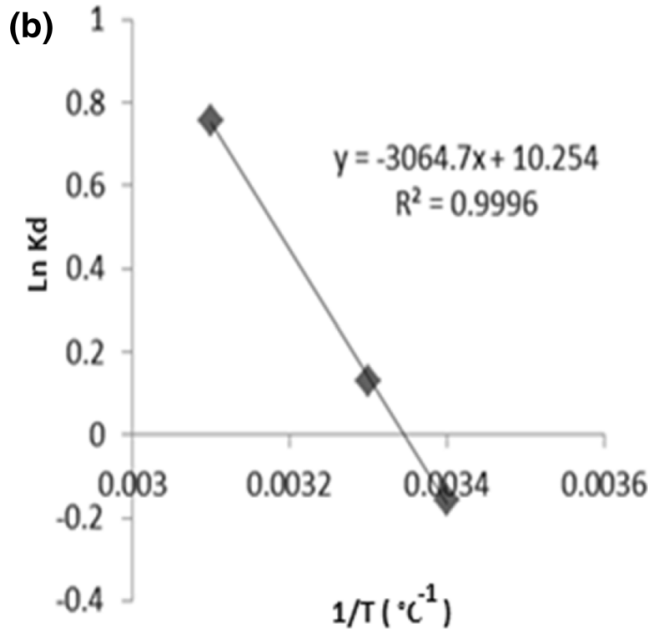

enthalpy of adsorption $\left(\Delta \mathrm{H}^{0}\right)$ can be computed from the following equations (Eqs. 13-15). $\Delta \mathrm{H}^{0}$ and $\Delta \mathrm{S}^{0}$ were taken as slopes and intercepts of the plot of $\ln K_{\mathrm{d}}$ versus $1 / T$ (Fig. 24), respectively. The results are gathered in
Table 10. The positive value of enthalpy $\Delta \mathrm{H}^{0}$ indicates that the adsorption is an endothermic process, and the positive value of entropy $\Delta S^{0}$ is attributed to an occurrence of a less ordered molecular arrangement of both carboxylate ion and 
Table 10 Thermodynamic parameters of the adsorption de $\mathrm{Cu}^{2+}$

\begin{tabular}{|c|c|c|c|c|c|c|c|}
\hline Sorbent & $T\left({ }^{\circ} \mathrm{C}\right)$ & $1 / T\left(\mathrm{~K}^{-1}\right)$ & $\ln K_{\mathrm{d}}$ & $\Delta \mathrm{G}^{0}\left(\mathrm{~kJ} \mathrm{~mol}^{-1}\right)$ & $\Delta \mathrm{H}^{0}\left(\mathrm{~kJ} \mathrm{~mol}^{-1}\right)$ & $\Delta \mathrm{S}^{0}\left(\mathrm{~J} \mathrm{~mol}^{-1} \mathrm{~K}^{-1}\right)$ & $R^{2}$ \\
\hline \multirow[t]{3}{*}{ PAA } & 20 & 0.0034 & -2.620 & 6.382 & \multirow[t]{3}{*}{18.96} & \multirow[t]{3}{*}{42.49} & \multirow[t]{3}{*}{0.992} \\
\hline & 30 & 0.0033 & -2.448 & 6.166 & & & \\
\hline & 45 & 0.0031 & -1.947 & 5.147 & & & \\
\hline \multirow[t]{3}{*}{ HQ-PAA } & 20 & 0.0034 & -0.158 & 0.384 & \multirow[t]{3}{*}{25.47} & \multirow[t]{3}{*}{85.25} & \multirow[t]{3}{*}{0.999} \\
\hline & 30 & 0.0033 & 0.130 & -0.327 & & & \\
\hline & 45 & 0.0031 & 0.757 & -2.001 & & & \\
\hline
\end{tabular}

Table 11 Adsorptiondesorption results

\begin{tabular}{|c|c|c|c|c|c|c|c|}
\hline \multirow[t]{2}{*}{ Metal ion } & \multirow[t]{2}{*}{ Cycle } & \multicolumn{2}{|c|}{ Amount of ion adsorbed (mg) } & \multicolumn{2}{|c|}{ Amount of ion desorbed $(\mathrm{mg})$} & \multicolumn{2}{|c|}{$D P(\%)$} \\
\hline & & PAA & HQ-PAA $^{\text {a }}$ & PAA & HQ-PAA ${ }^{\mathrm{a}}$ & PAA & HQ-PAA ${ }^{\mathrm{a}}$ \\
\hline \multirow[t]{3}{*}{$\mathrm{Pb}^{2+}$} & 1 & 6.98 & 20.82 & 6.85 & 20.59 & 98.16 & 98.91 \\
\hline & 2 & 6.89 & 20.62 & 6.76 & 20.32 & 98.14 & 98.54 \\
\hline & 3 & 6.86 & 20.52 & 6.73 & 20.19 & 98.07 & 98.41 \\
\hline \multirow[t]{3}{*}{$\mathrm{Cu}^{2+}$} & 1 & 3.52 & 17.17 & 3.46 & 16.92 & 98.20 & 98.54 \\
\hline & 2 & 3.41 & 17.10 & 3.35 & 16.81 & 98.17 & 98.30 \\
\hline & 3 & 3.38 & 16.85 & 3.30 & 16.55 & 97.58 & 98.19 \\
\hline \multirow[t]{3}{*}{$\mathrm{Cd}^{2+}$} & 1 & 2.89 & 12.65 & 2.86 & 12.54 & 99.08 & 99.12 \\
\hline & 2 & 2.86 & 12.60 & 2.83 & 12.47 & 98.94 & 99.02 \\
\hline & 3 & 2.84 & 12.57 & 2.81 & 12.44 & 98.72 & 98.97 \\
\hline
\end{tabular}

${ }^{\mathrm{a}}$ Modified PAA using $[\mathrm{BQ}] /[\mathrm{AA}]=1.25$ hydroquinone unit [42]. Negative values of Gibbs free energy $\left(\Delta G^{0}\right)$ indicate a favorable and spontaneous adsorption. Worthy of note is that, at $20^{\circ} \mathrm{C}$, no adsorption took place as the value of $\Delta \mathrm{G}^{0}$ is positive. At a working temperature, that is $30{ }^{\circ} \mathrm{C}$, adsorption occurred to a certain extent as $\Delta \mathrm{G}^{0}$ is $-0.327 \mathrm{~kJ} \mathrm{~mol}^{-1}$; however, a more favorable and spontaneous adsorption could happen at $40{ }^{\circ} \mathrm{C}\left(\Delta \mathrm{G}^{0}=-2.001 \mathrm{~kJ} \mathrm{~mol}^{-1}\right)$ :

$\Delta \mathrm{G}^{0}=-R T \ln K_{\mathrm{d}}$

$\ln K_{\mathrm{d}}=\frac{\Delta \mathrm{S}^{0}}{R}-\frac{\Delta \mathrm{H}^{0}}{R T}$

$K_{\mathrm{d}}=\frac{C_{0}-C_{e}}{C_{e}} \cdot \frac{V}{w}$

where

$R$ is the ideal gas constant $\left(8.314 \mathrm{~J} \mathrm{~mol}^{-1} \mathrm{~K}^{-1}\right)$,

$T$ is the absolute temperature $(\mathrm{K})$,

$K_{\mathrm{d}}$ is the equilibrium constant,

$C_{\mathrm{e}}$ is the equilibrium metal ion concentration $\left(\mathrm{mg} \mathrm{L}^{-1}\right)$.

\section{Desorption performance}

In the sake of reusability of the resin in adsorption of metals, the adsorption-desorption of metal ions was carried out. The desorption of metal-adsorbed resins was accomplished by treatment with $0.1 \mathrm{~N}$ nitric acid at $30{ }^{\circ} \mathrm{C}$. The results of adsorption-desorption of ions by the resins are gathered in Table 11. The results revealed that the capacity exchanges of the resins were retained even after three adsorption-desorption cycles for copper (II), lead (II), and cadmium (II) ions, hinting at the feasibility of reuse of the resins in the removal process. The desorption extents of these ions from PAA and HQ-PAA resins were substantially high and exceeding $98 \%$.

\section{Conclusions}

The application of oxidative decarboxylation of Minisci to the chemical modification of poly(acrylic acid) was successful. As expected, metallic adsorption of hydroquinonegrafted poly(acrylic acid) was greater than that of the virgin poly(acrylic acid). In addition, to achieve higher metal ion uptakes by poly(acrylic acid) and its modified resin, one needs to work under the following conditions: $\mathrm{pH} 5.4$, time $180 \mathrm{~min}$, and temperature $45^{\circ} \mathrm{C}$. Metallic adsorption by hydroquinone-modified poly(acrylic acid) resin occurred at temperatures of only higher than $30^{\circ} \mathrm{C}$. Finally, the adsorption-desorption results suggest the utilization of the 
hydroquinone-modified poly(acrylic acid) as a cation exchange resin.

Open Access This article is distributed under the terms of the Creative Commons Attribution 4.0 International License (http://crea tivecommons.org/licenses/by/4.0/), which permits unrestricted use, distribution, and reproduction in any medium, provided you give appropriate credit to the original author(s) and the source, provide a link to the Creative Commons license, and indicate if changes were made.

\section{References}

1. Francis S, Kumar M, Varshney L (2004) Radiation synthesis of superabsorbent poly(acrylic acid)-carrageenan hydrogels. Rad Phys Chem 69:481-486

2. Hussain T, Ranjha NM, Shahzad Y (2011) Swelling and controlled release of tramadol hydrochloride from a $\mathrm{pH}$-sensitive hydrogel. Des Monom Polym 14:233-249

3. Adnadjevic B, Jovanovic J (2008) Novel approach in investigation of the poly(acrylic acid) hydrogel swelling kinetics in water. J Appl Polym Sci 107:3579-3587

4. Moulay S, Boukherissa M, Abdoune F, Benabdelmoumene FZ (2005) Low molecular weight poly(acrylic acid) as a salt scaling inhibitor in oilfield operations. J Iran Chem Soc 2:212-219

5. Bensacia N, Moulay S (2012) Functionalization of polyacrylic acid with tetrahydroxybenzene via a homolytic pathway: application to metallic adsorption. Intern J Polym Mater 61:699-722

6. Adewuyi S, Ondigo DA, Zugle R, Tshentu Z, Nyokong T, Torto N (2012) A highly selective and sensitive pyridylazo-2-naphtholpoly(acrylic acid) functionalized electrospun nanofiber fluorescence "turn-off" chemosensory system for $\mathrm{Ni}^{2+}$. Anal Meth 4:1729-1735

7. Müller M, Keßler B, Fröhlich J, Poeschla S, Torger B (2011) Polyelectrolyte complex nanoparticles of poly(ethyleneimine) and poly(acrylic acid): preparation and applications. Polymers 3:762-778

8. Li D, Jiang Y, Li C, Wu Z, Chen X, Li Y (1999) Self-assembly of polyaniline/polyacrylic acid films via acid-base reaction induced deposition. Polymer 40:7065-7070

9. Lu X, Yu Y, Chen L, Mao H, Wang L, Zhang W, Wei Y (2005) Poly(acrylic acid)-guided synthesis of helical polyaniline microwires. Polymer 46:5329-5333

10. Moulay S, Mehdaoui R (2004) Hydroquinone/catechol-bearing polyacrylic acid: redox polymer. React Funct Polym 61:265-275

11. Xu Y, Lin Y, Zhuang L, Lin J, Lv J, Huang Q, Sun J (2013) Bleomycin loaded magnetite nanoparticles functionalized by polyacrylic acid as a new antitumoral drug delivery system. BioMed Res Intern. 2013;Article ID 462589:5. doi:10.1155/2013/ 462589

12. Sakaguchi Y, Nishino J, Tamaki K, Nagae T (1968) Preparation and potentiometric titration of several polymer carboxylic acids. Kobunshi Kagaku 25:761-768

13. Moulay S, Bensacia N, Garin F, Fechete I, Boos A (2013) Polyacrylamide-based Sorbents for the removal of hazardous metals. Adsorpt Sci Technol 38:691-710

14. Moulay S, Bensacia N, Garin F, Fechete I, Boos A (2014) Synthesis of polyacrylamide-bound hydroquinone via a homolytic pathway: application for removal of heavy metals. CR Chim 17:849-859

15. Bertini F, Caronna T, Galli R, Minisci F, Porta O (1972) New processes for the homolytic alkylation of protonated heteroaromatic bases. Chim Ind (Milan) 54:425-426
16. Bensacia N, Fechete I, Moulay S, Hulea O, Boos A, Garin F (2014) Kinetic and equilibrium studies of lead (II) adsorption from aqueous media by KIT-6 mesoporous silica functionalized with COOH. CR Chim 17:869-880

17. Bensacia N, Fechete I, Moulay S, Debbih-Boustila S, Boos A, Garin F (2014) Removal of cadmium (II) from aqueous media using COOH/TUD-1 mesoporous solid. Kinetic and thermodynamic studies. Environ Eng Manag J 13:2675-2686

18. Shah BA, Shah AV, Bhatt RR (2007) Studies of chelation ionexchange properties of copolymer resin derived from salicylic acid and its analytical applications. Iran Polym J 16:173-184

19. Bhatt RR, Shah BA (2015) Sorption studies of heavy metal ions by salicylic acid-formaldehyde-catechol terpolymeric resin: isotherm, kinetic and thermodynamics. Arab J Chem $8: 414-426$

20. Moulay S, Mehdaoui R (2006) Poly(methacrylic acid)-bound dihydroxybenzene units: redox polymers. J Appl Polym Sci 100:954-961

21. Kara A, Uzun L, Besirli N, Denizili A (2004) Poly(ethylene glycol dimethacrylate- $N$-vinyl imidazole) beads for heavy metal removal. J Hazard Mater 106 B:93-99

22. Bulut Y, Akçay G, Elma D, Serhatli IE (2009) Synthesis of claybased superabsorbent composite and its sorption capability. J Hazard Mater 171:717-723

23. Minisci F, Porto O (1974) Advances in homolytic substitution of heteroaromatic compounds. In: Katritzky AR, Boulton AJ (eds.) Advances in heterocyclic chemistry, vol 16. Academic Press, Inc, New York, pp 123-180

24. Minisci F (1976) Recent aspects of homolytic aromatic substitutions. Top Curr Chem 62:1-48

25. Minisci F, Citterio A (1980) Polar effects in free-radical reactions in synthetic chemistry. In: Williams GH (ed.) Advances in free radical chemistry, vol 6. Heyden \& Sons Ltd, London, $65-153$

26. Antonjetti M, Conrad J (1994) Synthesis of very highly ordered liquid crystalline phases by complex formation of polyacrylic acid with cationic surfactants. Angew Chem Intern Ed 33:1869-1870

27. Antaya H, Richard-Lacroix M, Pellerin C (2010) Electrospinning as a new method for preparing pure polymer complexes. Macromolecules 43:4986-4990

28. Neira A, Tarraga M, Catalan R (2007) Degradation of polyacrylic acid by Fenton's reagent. J Chil Chem Soc 52:1314-1317

29. Tekin N, Dinçer A, Demirbas Ô, Alkan M (2006) Adsorption of cationic polyacrylamide onto sepiolite. J Hazard Mater B134:211-219

30. Zhao G, Zhang H, Fan Q, Ren X, Li J, Chen Y, Wang X (2010) Sorption of copper (II) onto super-adsorbent of bentonite-polyacrylamide composites. J Hazard Mater 173:661-668

31. Yetimoğlu EK, Kahraman MV, Ercan OE, Akdemir ZS, Apohan NK (2007) $N$-vinylpyrrolidone/acrylic acid/2-acrylamido-2methylpropane sulfonic acid based hydrogels: synthesis, characterization and their application in the removal of heavy metals. React Funct Polym 67:451-460

32. Zheng Y, Hua S, Wang A (2010) Adsorption behavior of $\mathrm{Cu}^{2+}$ from aqueous solutions onto starch-g-poly(acrylic acid)/sodium humate hydrogels. Desalination 263:170-175

33. Bunting JW, Thong KM (1970) Stability constants for 1:1 metalcarboxylate complexes. Can J Chem 48:1654-1656

34. Kostić I, Anđelković T, Nilkolić R, Bojić A, Purenović M, Blagojević Anđelković D (2011) Copper(II) and lead(II) complexation by humic acid and humic S.-like ligands. J Serb Chem Soc 76:1325-1336

35. Deleuze H, Schultze X, Sherrington DC (2000) Synthesis of porous supports containing $N$-( $p$-hydroxyphenyl)- or $N$-(3-4-dihydroxybenzyl) maleimide-anchored titanates and application as 
catalysts for transesterification and epoxidation reactions. J Polym Sci Part A Polym Chem 38:2879-2886

36 Yılmaz SV, Kul D, Erdöl M, Özdemir M, Abbasoğlu R (2007) Synthesis of a novel crosslinked superabsorbent copolymer with diazacyclooctadecane crown ether and its sorption capability. Eur Polym J 43:1923-1932

37 Lagergren S (1898) Zur theorie der sogenannten adsorption gelöster stoffe, K Sven Vetenskapsakad. Handl 24:1-39

38 Ho YS, McKay G (1999) Pseudo-second order model for sorption processes. Proc Biochem 34:451-465

39 Freundlich HMF (1906) Uber die adsorption in losungen. Z Phys Chem (Leipzig) 57:385-470
40 Langmuir I (1916) The constitution and fundamental properties of solids and liquids Part I. Solids. J Am Chem Soc 38:2221-2295

41 Temkin MI, Pyzhev V (1940) Kinetics of ammonia synthesis on promoted iron catalyst. Acta Phys Chim USSR 12:327-356

42 Zhao X, Zhang G, Jia Q, Zhao C, Zhou W, Li W (2011) Adsorption of $\mathrm{Cu}(\mathrm{II}), \mathrm{Pb}(\mathrm{II}), \mathrm{Co}(\mathrm{II}), \mathrm{Ni}(\mathrm{II})$, and $\mathrm{Cd}(\mathrm{II})$ from aqueous solution by poly(aryl ether ketone) containing carboxyl groups (PEK-L): equilibrium, kinetics, and thermodynamics. Chem Eng J 171:152-158 